\title{
1. Unvermeidliche Fragen der Pausaniasforschung
}

„Was stellt das Werk vor? ist gewöhnlich die erste Frage, die sich angesichts eines Gemäldes, eines Reliefs, eines Kupferstiches oder sonst irgend eines anderen Bildwerkes einstellt. Die Antwort darauf suchen wir in unserer eigenen Vorstellungswelt oder Erinnerungen aus der überlieferten Literatur. Ist es doch namentlich in den vergangenen Jahrhunderten selten, dass ein Künstler nicht aus der heiligen Schrift oder Mythologie geschöpft, nicht die Dichter oder Geschichtsschreiber zu Rate gezogen hat. Die Ikonographie hat sich also mit allen möglichen Quellen der Darstellung zu befassen, religiöses Dogma, Legende oder Mythus, Epos, Chroniken und Annalen; aber auch Phantasieprodukte aller Art, philosophische Abhandlungen, Moralpredigten, umfassende Encyklopädien, wie z.B. das Speculum des Vincenz von Beauvais; ja, sogar Flugschriften - Pamphlete und Satiren - geben oft willkommenen Aufschluss." (Aby Warburg) ${ }^{1}$

Die zehn Bücher, die von den auf dem griechischen Festland gelegenen Regionen Attika, Argolis, Lakonien, Messenien, Elis, Achaia, Arkadien, Boiotien und Phokis handeln, sind das einzige erhaltene Werk des Pausanias. Sein Titel ist bei Stephanus von Byzanz als Periegeses tes Hellados überliefert. ${ }^{2}$ Die Abfassungszeit des Werkes wird zwischen 161 und 180 n. Chr., also in der Regierungszeit Mark Aurels angesetzt. ${ }^{3}$ Es gibt einen mehr oder minder fest umrissenen Problemhorizont, den man unter der Überschrift unvermeidliche Fragen der Pausaniasforschung fassen kann. Einige der Fragen sind auch gegenwärtig noch Gegenstand jeder Publikation. Allerdings werden andere nicht mehr problematisiert, und zwar die im Folgenden von mir im Anschluss an die ältere Forschung diskutierten Fragen. In den gegenwärtigen Forschungen interessieren besonders nur noch zwei Fragen: Die nach der Identität des Autors und nach der Gattung, die allerdings letztgültig auch nicht zu klären sind, vor allem aufgrund eines nicht vorhandenen, >fehlenden wurde angesichts des nicht existierenden Proöms zur Periegese sowohl die Ansicht vertreten, dass Pausanias absichtlich kein Proöm geschrieben habe, als

1 Abgedruckt in: Schmidt/Wuttke, 1989, 65 (= Internationaler Kunsthistorischer Kongress in Innsbruck vom 9. bis 12. September 1902, Mr. C. de Mandach - Paris: Bericht des Vorstandes der Internationalen Gesellschaft für Ikonographische Studien, 24/25).

2 Im Zusammenhang mit der Diskussion um die Identität des Pausanias wurde von Pasquali, 1913, 222 in Anlehnung an die Angaben bei Stephanus von Byzanz vermutet, dass Pausanias außerdem verschiedene Ktiseis, Gründungsgeschichten syrischer Städte geschrieben habe.

3 Diller, 1983, 138. 
auch, dass es zwar ein Proöm gegeben habe, dieses aber verloren gegangen, d.h. nicht überliefert ist. Man hat außer wegen des fehlenden Proöms auch wegen des als abrupt empfundenen Endes für eine unvollständige Überlieferung der Periegese plädiert. Das abrupte Ende lässt sich m. E. aber mit der Rätseltheorie in Verbindung bringen und dann handelt es sich nicht um ein abruptes Ende, sondern um einen abschließenden lógos am Ende des Gesamtwerkes, der genau darauf verweist: Ein beinahe Erblindeter entsiegelt eine versiegelte Schrift. Ich werde davon ausgehend meinen eigenen Forschungsansatz begründen, dass es sich bei der Periegese um ein kaschiertes Städtelob und -tadel handelt, das vom Leser entschlüsselt werden soll.

Obwohl man die Fragen nach der Identität des Autoren und der Gattung so (unvollständige Überlieferung) oder so (Verrätselung) nicht eindeutig beantworten kann, muss man sich als Forscher mit diesen beiden Fragen befassen, denn von der Art ihrer Beantwortung hängt das Verständnis der Periegese und den Intentionen ihres Verfassers ab. Das Buch von Habicht über Pausanias aus dem Jahr 1985 hat einige von ihm so möglicherweise gar nicht intendierte hermeneutische Konsequenzen für die nachfolgenden Forschungen gehabt. Sie bestehen vor allem darin, dass ihm nachfolgende Forscher all das, was früher im Zusammenhang mit der Zweiten Sophistik gebracht worden ist, seitdem nicht mehr eigens diskutieren, sondern ausblenden oder gar nicht mehr thematisieren: Die sogenannte Lückenhaftigkeit der Periegese und die so genannten Exkurse werden nur noch wenig, die früher so genannte Buntschriftstellerei respektive die Kompilationsthese und die Verschiedenartigkeit der Bücher werden fast gar nicht mehr diskutiert. Beobachtungen zum Sprachstil und der Stilmischung sind hingegen Thema der Pausaniasforschung geblieben. Damit zusammenhängende Probleme werden teilweise weiter diskutiert, teilweise neu gefunden; dabei kommt es zu Wiederholungen der Ergebnisse älterer Forschungen, denen sich neuere Forschungen zumeist nicht bewusst sind. Dies betrifft auch die Gattungsproblematik und Identitätsfrage. Es lassen sich nun allerdings triftige Gründe dafür anführen, an die Forschungsfragen des späten 19. und frühen 20. Jahrhunderts anzuknüpfen, ohne die alten Schlussfolgerungen zu übernehmen. An neueren Arbeiten haben sich für die vorliegende Untersuchung die Überlegungen von Elsner zur Frage nach der Verrätselung des Textes der Periegese (gibt es einen Schlüssel?) und nach der Bedeutung der Einnahme des Gestus des reisenden frommen Pepaideumenos sowie Goldhills Konzept der Kultur des Sehens (>culture of viewings) als besonders relevant erwiesen. Dies werde ich in den folgenden Kapiteln im einzelnen ausführlich begründen. 


\subsection{Ungeklärte Identität des Autors}

Im Hinblick auf die ungeklärte Identität des Autors stehen sich seit Beginn der Pausaniasforschung zwei Positionen gegenüber: Erstens die Annahme, ${ }^{4}$ es könne aus dem Text heraus auf seine Identität geschlossen werden und zweitens die Auffassung, die ich auch in der vorliegenden Untersuchung vertrete, dass nämlich genau dieses Verfahren zu keinem verlässlichen Ergebnis führt, da der Autor allenfalls Anspielungen auf seine Identität macht. Diese sind aber nicht gleichzusetzen mit 'Sprecherrollen`, die Pausanias einnimmt, wie z.B. die zeittypischen des frommen Pepaideumenos und Exegeten, und die seinen Schilderungen Autorität verleihen sollen. Den gleichen Effekt hat übrigens auch der reflektierte und gekonnte Gebrauch anderer Texte, die seine Darstellung plausibel machen (sollen). Das spricht dafür, dass man es mit einem gelehrten und kundigen Autor zu tun hat, den man entsprechend der Zweiten Sophistik zuzurechnen hätte. ${ }^{5}$ Der Leser soll die Identität des Autoren erschließen und auch, wen er mit seinem Werk imitiert.

In der neueren Forschung hat die früher eher selten favorisierte Variante, ${ }^{6}$ dass Pausanias ein ansonsten unbekannter Autor aus Kleinasien ist, inzwischen nahezu kanonische Geltung. ${ }^{7}$ Sämtliche Argumente, die man für die These heranzog und auch überhaupt nur heranziehen kann, werden aus dem Text der Periegese selbst gewonnen. Wie bereits Diller vermerkte, belegen die in diesem Kontext immer wieder zitierten Passagen jedoch nicht mehr, als dass Pausanias zeitweise in Kleinasien gelebt haben könnte, aber selbst das ist

4 Habicht, 1985, 21. Habicht hat das bis heute zumeist praktizierte Verfahren erneut inauguriert, Aufschlüsse über Pausanias allein aus dem Werk zu gewinnen.

5 Habicht, 1985, 20 lehnte die Identifikation mit einem der bekannten Sophisten rigoros $\mathrm{ab}$; man wisse gar nichts über die Person. Die unglückliche Gleichsetzung mit Pausanias von Damaskus sei aufgegeben worden und so bestehe kein Grund mehr, an seiner Herkunft aus Kleinasien zu zweifeln (ebenda 25).

6 Kalkmann, 1886, 11, Anm. 1: „Fuit enim Damascenus, sagt Wernicke schlankweg (De Pausaniae stud. Herodot. Berlin 1884, p. 5) und beruft sich auf Westermann (N. Jahrbücher für Philol. 1839 p. 25 ff.), der indes den Damascener keineswegs mit unserem Pausanias identifiziert. Sicher ist, dass dieser sich in Ionien aufhielt, als er seine Periegese schrieb $(5,13,7 ; 9,21,6)$; umso auffallender erscheint seine Vertrautheit mit Syrien und dessen Denkmälern, worüber oft beiläufige Bemerkungen einfließen $(2,1,8 ; 5,7,4 ; 6,24,8 ; 8,16,5 ; 10,29,4)$. Schon Holsten vermutete, dass unser Pausanias identisch sei mit dem Verfasser von peri Antiocheias (vgl. Siebelis zu 5,7,4). Auch Stephanos unterscheidet in seinen Zitaten den Syrer nicht von unserem Pausanias." Diller, 1983 (The Authors named Pausanias), 146 plädierte demgegenüber für zwei verschiedene Personen, einen Pausanias von Damaskus und einen Pausanias von Antiochia.

7 Habicht, 1985, 25; Elsner, 1992, 28; Whittaker, 2001, 124; Jones 2001, 33: Pausanias aus Magnesia am Sipylus. 
keineswegs eindeutig. ${ }^{8}$ Nicht zuletzt deshalb hatte er selber die heute zumeist vertretene Auffassung, ${ }^{9}$ Pausanias stamme aus Magnesia am Sipylos, für ausgesprochen unwahrscheinlich gehalten. Diller bezeichnete diesen seinerzeit von Siebelis in die Diskussion gebrachten Vorschlag sogar als Irrtum. ${ }^{10}$ Diller selbst war nach Diskussion der verschiedenen Möglichkeiten zu der Ansicht gelangt, dass Pausanias durchaus mit einem der namentlich bekannten Sophisten identifiziert werden könne, nur es eben nicht eindeutig zu entscheiden sei, wie viele Personen bzw. Sophisten dieses Namens es gegeben habe und mit welcher dieser Pausanias zu identifizieren sei. ${ }^{11}$ Er hatte als plausibelste Variante, Pausanias sei der Sophist aus Damaskus, diskutiert. ${ }^{12}$ Das stärkste Argument für die Identifizierung von Pausanias mit einem Sophisten syrischer Herkunft sah Diller in den namentlichen Zitaten aus der Periegese bei dem Pausaniasschüler Aelian (Varia historia 12,61 = Periegese 8,27,14 und 8,36,6), die schwerlich, so Diller, durch die Annahme einer Emendation einfach übergangen und damit weginterpretiert werden könnten. ${ }^{13}$ Was Diller dazu brachte, konkret die Einordnung Pausanias von Damaskus in Frage zu stellen und statt dessen einen weiteren Pausanias, und zwar von Antiochia anzunehmen, war seine Vermutung, Pausanias von Damaskus könne der Autor einer bis dato Ps.-Skymnos zugeordneten Schrift sein, die sicher um 100 v. Chr. datiert werden kann. Folglich könne Pausanias von Damaskus nicht im 2. Jh. n. Chr. die Periegese geschrieben haben. ${ }^{14}$ Aber auch hierin ist er sich keineswegs sicher, weil das ein ungewöhnlicher bis unwahrscheinlicher Befund sei, wie er ausdrücklich betonte. Aufgrund der hier vorgestellten Überlegungen Dillers scheint es mir jedenfalls methodisch problematisch, textimmanente Argumente für die kleinasiatische Variante seiner Herkunft gegen textexterne Argumente für eine durchaus mögliche syrische Herkunft auszuspielen. ${ }^{15}$

Bis zur weiteren Diskussion der Identitätsfrage im dritten Teil der Arbeit (Kaiserzeitliche Sophisten mit dem Namen Pausanias) möchte ich auf Aspers Überlegungen hinweisen, der hinsichtlich der Probleme der unklaren Bio-

8 Diller, 1983 (The Authors named Pausanias), 139; (Pausanias in the Middle Ages), 149.

9 So z.B. Bowie, 2001, 24, Jones, 2004, 14 ff. und zuletzt Hutton, 2005, 9 f.

10 Diller, 1983 (The Authors named Pausanias), 139.

11 Diller, 1983 (The Authors named Pausanias), 148.

12 Diller, 1983 (The Authors named Pausanias), 141-147.

13 Diller, 1983 (The Authors named Pausanias), 141.

14 Diller, 1983 (The Authors named Pausanias), 147. Diller hatte Zweifel an seiner Rekonstruktion, weil ihm ein Syrer als Autor eines dem bithynischen König Nikomedes gewidmeten Periplus des Mittelmeeres ,rather unexpected“ erschien.

15 So Jones, 2001, 33. Bowie 2001, 23 f. Jüngst hat sich Hutton, 2005, 9 f. der Auffassung angeschlossen, Pausanias stamme aus Magnesia, jedenfalls aber aus Kleinasien, und zwar weil er sich dem Text nach zu urteilen dort besonders gut auszukennen scheine. 
graphie eines anderen griechischen Autoren, Kallimachos, nachdrücklich davor warnte, Kallimachos' eigene Werke nach historischen Fakten abzusuchen. Dies bleibe wie bei jedem literarischen Text grundsätzlich problematisch, besonders wenn es sich um einen elusiven Autor handelt. ${ }^{16}$

\subsection{Gab es eine >Gattung` Periegese?}

Ähnlich wie bei der Problematik mit der nicht zweifelsfrei zu klärenden Identität des Pausanias kommt man bei dem Versuch einer Gattungsbestimmung der Periegese letztlich immer wieder zu Aporien. Und obwohl diese Aporien beim Bestimmen von Gattung und Autor in beiden Fällen nicht gelöst werden können, bleiben sie ein unumgängliches Problem für jeden Forscher. Pausanias muss die Form der Periegese oder das Vorbild eines Periegeten bewusst gewählt haben. ${ }^{17}$ Das hatten zu Anfang des 20. Jh. schon Pasquali und Robert angenommen, waren allerdings von einer Mehrzahl von Vorbildern ausgegangen bzw. einer mehr oder minder festen und klar umrissenen Gattung Periegese. In diesem Zusammenhang erscheint daher auch heute noch die Frage interessant, weshalb Pausanias sich so entschieden hat bzw. was eine Periegese als literarische Darstellungsweise für ihn attraktiv machte. Ich werde dieser Frage im dritten Teil der vorliegenden Untersuchung deshalb noch ausführlich nachgehen.

Die ältere Forschung zur Gattungsproblematik der Periegese nahm folgenden, letztlich in Aporien mündenden Verlauf: Erstens die Erschließung und Rekonstruktion der vermuteten Gattung Periegese über das „einzige vollständig erhaltene Werk dieser Literaturgattung“" ${ }^{18}$ die Periegese des Pausanias, zweitens die Ermittlung sogenannter gattungsuntypischer Elemente des so gewonnenen Gattungsbegriffes innerhalb der Periegese des Pausanias, ${ }^{19}$ drittens die Diskussion der sichtbar gemachten Besonderheiten, die als Abweichungen desselben Werkes vom postulierten Standard gewertet wurden. ${ }^{20}$ Auffallend ist, dass die meisten Vertreter der älteren Forschung, die sich mit der Gattungswahl des Pausanias auseinandersetzten, zu dem Ergebnis kamen, dass er die Form der Periegese auf eine sehr spezielle Weise adaptiert habe, was entsprechend positiv oder negativ bewertet wurde. Geht man von den unterschiedlichen Ansätzen aus, eine Gattung Periegese bestimmen zu wollen, so spiegelt sich diese Irritation über mögliche Varianten deutlich in der Unge-

16 Asper, 2004, 3.

17 So auch die Annahme von Elsner, 2001, 7.

18 Bischoff, s.v. Perieget, RE 19.1, 727.

19 Pasquali, 1913, 164.

20 Kalkmann, 1886, 278 ff.; Strid, 1976, 102 f. 
wissheit wider, welchen Stellenwert man der Periegese des Pausanias im Rahmen dieser Gattungsverortung beizumessen hat. Während einerseits Pausanias' Werk als einziges vollständig erhaltenes Exemplar einer ansonsten untergegangenen bzw. nicht mehr greifbaren Gattung zum maßgeblichen Paradigma erhoben wurde, von dem aus man versuchte, die Struktur anderer, dem Titel und/oder durch Fragmente nach als Periegese bekannter Werke zu rekonstruieren, gab es andererseits die Auffassung, dass die Periegese des Pausanias von vornherein aus allen Überlegungen zur Gattung Periegese ausgeschieden werden müsse. Sie sei in vielerlei Hinsicht untypisch oder eine Ausnahme, sofern man dies aus dem Vergleich mit anderen fragmentarisch erhaltenen Texten oder bloß Titeln zu schließen können glaubte.

Ohne die Gattungskonzeptionen zur Periegese und ihre Problematik im Detail zu erläutern, möchte ich folgende Konstruktionen nennen: Als unerlässlich für den Begriff der sogenannten antiquarischen Periegese wurde von Bischoff vermerkt, dass in dieser literarischen Form Wissen vermittelt werde, das der Leser auf Wegen, die er macht oder machen könne, aufnehme, wodurch der Eindruck bei dem modernen Leser erzeugt werde, es handele sich um einen Reise- oder Fremdenführer. Die Fragmente von Werken des Polemon von Ilion mit dem Beinamen Perieget, die Bischoff dieser Definition zugrunde legte, sprechen seiner Auffassung nach dafür, dass Polemon mit der Abfassung von Periegesen eine wissenschaftliche Absicht verfolgte. ${ }^{21}$

Pasquali hatte die Ansicht vertreten, die Periegetik sei eine Kunstform, die sich aus der altionischen Geographie und Historiographie nach Hekataios und Herodot entwickelt habe. Er unterschied dabei antiquarisch, geographisch und topographisch „gefärbte“ Periegesen. ${ }^{22}$ Als typische Elemente altionischer Geschichtsschreibung, die in die Periegesen eingegangen seien, hat Pasquali vor allem Chorographie (Landschaftsbeschreibung, verbunden mit ethnographischen Beobachtungen), Beschreibung von Wundern (Thaumasia, Paradoxa) sowie die persönliche Erkundung durch den jeweiligen Autor genannt; ab dem 2. Jh. v. Chr. habe sich dann - dies schloss er aus dem Aufkommen des „schönen Sprachstill“ - ein Wandel von der reinen Sachlichkeit zur Literaturform vollzogen. ${ }^{23}$ Bereits Gurlitt hatte Ende des 19. Jahrhunderts die immer wieder zumeist stillschweigend übernommene Charakterisierung einer Periegese festgeschrieben, und zwar als basierend auf Angaben zu Topographie, Gebäuden, Kunstwerken und Denkmälern; für „die Periegetik“ als Darreichungsform sei dabei typisch und bezeichnend der Wechsel zwischen Mo-

21 Bischoff, RE-Artikel Perieget, Bd. 19.1, $728 \mathrm{f}$.

22 Pasquali, 1913, $187 \mathrm{f}$.

23 Pasquali, 1913, 212. 
numenten (theorémata) und Erläuterungen (lógoi) gewesen, die den Kern aller Periegesen gebildet hätten. ${ }^{24}$

Der Begriff Gattung kann daher nur ein Hilfsmittel sein, da man aufgrund des äußerst mangelhaften Überlieferungszustandes anderer, nicht nachweislicher Periegesen kaum von einer festen Gattung sprechen kann. ${ }^{25}$ Dieses begriffliche Hilfsmittel trägt der Tatsache Rechnung, dass bereits in der Antike selbst verschiedene Literaturformen unterschieden wurden: Historiographie, Rhetorikhandbücher, Geographie, Romane etc. Wenn eine dieser Gattungen von dem Autor gewählt wurde, hat dies zwangsläufig etwas mit schriftstellerischer Intention zu tun.

Sofern neuere Forschungen die Gattungsproblematik in den Blick nehmen, sehen sie die Periegese aufgrund der Textform und der unterschiedlichen 'Einfärbungen als Variante anderer Literaturgattungen an. Wie Forschungen im Anschluss an Habichts Pausaniasmonographie herausgestellt haben, enthält die Periegese des Pausanias Elemente von Historiographie, Geographie, Mythographie, historischem Epos und Pilgerbericht, um hier die besonders prominent untersuchten Gattungen zu nennen. Es gibt in der Tat zahlreiche historiographische Textpassagen in der Periegese, ${ }^{26}$ ebenso wie geographische. ${ }^{27}$ Quantitativ stellen die sogenannten mythographischen Abschnitte gleichfalls ein bedeutendes Element dar. ${ }^{28}$ Mit den mythischen Genealogien leitet Pau-

24 Gurlitt, 1890, VI.

25 D.h. über die von der älteren Forschung (re-)konstruierten Parallelbeispiele für Periegesen hinaus.

26 Besonders im 7. Buch (Achaia), exempli causa 7,13,1 f.: „Wiederum nahmen die Achaier diese Widersprüche zum Anlass, den Lakedaimoniern den Krieg zu erklären. Gegen Sparta sammelte sich ein Heer unter Damokritos, der damals zum Strategen der Achaier gewählt worden war. Um die gleiche Zeit traf in Makedonien ein Heer der Römer ein; sein Befehlshaber war Metellos, um gegen Andriskos, den Sohn des Perseus und Enkel des Philippos, Krieg zu führen, der von den Römern abgefallen war. Der Krieg in Makedonien kam zur schnellsten Entscheidung, wie es sich die Römer nur wünschen konnten. (2) Metellos beauftragte die vom römischen Senat für Angelegenheiten in Asien entsandten Männer, vor ihrem Übersetzen nach Asien mit den Führern der Achaier in Verhandlungen einzutreten und ihnen zu verbieten, die Waffen gegen Sparta zu erheben; außerdem sie aufzufordern, die Ankunft der Männer aus Rom abzuwarten. Denn diese seien mit dem Auftrag abgeschickt worden, Richter zwischen den Lakedaimoniern und Achaiern zu sein."

27 Z.B. 7,26,10 f.: „Ein gerader Weg geht aus Aigeira vom Heiligtum des Zeus steil übers Gebirge. [...] Die Länge des Wegs beträgt vierzig Stadien; er führt nach Phelloë, einem unscheinbaren Städtchen. Dies war nicht immer bewohnt, auch als die Ionier das Land beherrschten. Die Umgebung von Phelloë ist zum Weinanbau geeignet. Der felsige Teil des Landes hat Eichen und Wild, Hirsche und Wildschweine. (11) Wenn irgendeine der griechischen Städte reichlich von Wasser durchflossen wird, dann muss man Phelloë zu diesen rechnen."

28 So 1,2,6 (Athen): „Mit der Herrschaft des Amphiktyon verhält es sich folgendermaßen: Sie sagen, Aktaion sei der erste König im heutigen Attika gewesen. Nach seinem Tod 
sanias in der Periegese die Darstellung der einzelnen griechischen Stämme sowie Städte entweder jeweils ein oder integriert sie in die Gesamtdarstellung. Als einziges Beispiel für Einflüsse des historischen Epos als partiell fiktive und an heroischen Figuren orientierte Geschichtsschreibung ist Buch 4 (Messenien) heranzuziehen. ${ }^{29}$ Beispiele für die fünfte Gattung, den Pilgerbericht, lassen sich, je nachdem, ob man die Existenz einer solchen Gattung für die Antike akzeptiert oder nicht, sehr zahlreich oder gar nicht bringen. ${ }^{30}$ Ich werde diese Frage und entsprechende Forschungspositionen in dem Kapitel `Die Periegese als Pilgerbericht $<$ diskutieren.

Wenn man die oben zitierten Passagen jeweils als Einlagerungen von Historiographie, Geographie, Mythographie, historischem Epos und Pilgerbericht in die Periegese ansieht, wird der Begriff Periegese allerdings unscharf und man gewinnt den Eindruck, als sei eine Periegese etwas von allem und nichts Eigenes. Dieser Sichtweise entspricht die implizite und explizite Bezugnahme des Pausanias auf andere Autoren und ihre Werke, d.h. eindeutig fassbarer Genres (Historiographie, Genealogie, Geographie, sogenannte Kultschriftsteller etc.), die Pausanias durch einen eigentümlichen Sprachstil miteinander verwoben haben könnte.

Betrachtet man die Probleme, die sich aus den von anderen Disziplinen vorgebrachten Vorschlägen zur Gattung ergeben, so erscheint es nicht unbedingt ein Desiderat religionswissenschaftlicher Forschung zu sein, einen weiteren Gattungsbegriff einzuführen, der seinerseits nun das Thema Religion in der Periegese des Pausanias überbetonen würde. Die Problematik eines rein religionswissenschaftlichen Ansatzes, der von der Gattung seinen Ausgang nähme, ist, dass es unter diesem Gesichtspunkt dann praktisch keinerlei Ver-

folgte ihm Kekrops in der Herrschaft, indem er mit der Tochter des Aktaion vermählt war. Er selbst hatte drei Töchter, Herse, Aglauros und Pandrosos, und einen Sohn Erysichthon. Dieser wurde nicht König der Athener, sondern starb noch zu Lebzeiten seines Vaters, und die Herrschaft des Kekrops ging auf Kranaos über, da er unter den Athenern über die meiste Macht verfügte. Kranaos soll unter anderen Töchtern die Atthis gehabt haben." Vgl. auch 2,4,3 (Korinth) und 7,18,2 (Patrai).

29 4,6,3: „Den einen einzigartigen Messenier, dessentwegen ich diesen ganzen Exkurs über Rhianos und Myron mache, den Aristomenes, der als erster und ganz besonders den messenischen Namen berühmt machte, diesen Mann hat der Prieneer in die Darstellung eingeführt, und im Epos des Rhianos ist Aristomenes nicht weniger glanzvoll als Achill bei Homer in der Ilias. Da sie nun etwas derart Verschiedenes sagen, blieb mir nur übrig, mich der einen der beiden Erzählungen anzuschließen und nicht beiden zugleich, und zwar scheint mir Rhianos' Dichtung über das Zeitalter des Aristomenes glaubwürdiger zu sein. (4) Dass Myron sich nicht darum bekümmert, wenn er Falsches und Unwahrscheinliches zu erzählen scheint, kann man auch sonst erkennen und in diesem seinem messenischen Buch besonders."

30 Z.B. Beschreibung des nächtlichen Kultgeschehens der Arrhephoroi beim Athenafest 1,27,3 (Athen); Schilderung der Prozession beim Peithokult in 2,7,7 (Sikyon); 7,18,10-13: Kult und Prozession für die Artemis Laphria (Patrai). 
gleichsmöglichkeiten mit anderen Autoren bzw. Werken gibt, denn die Periegese des Pausanias ist die einzige ihrer Art im 2. Jh. n. Chr. und damit eine Ausnahme. Anstelle eines religionswissenschaftlichen Gattungskonzeptes setze ich in meiner Untersuchung jedoch gerade auf solche Vergleichmöglichkeiten und zeitlichen Kontexte, die für Pausanias neue Perspektiven des Verständnisses eröffnen sollen. Dies tue ich in Anlehnung an methodische Überlegungen des Kunsthistorikers Grohé zu dem Künstler Rembrandt: Im Rahmen seiner Kritik an der Rembrandtforschung verweist er darauf, dass Rembrandt lange Zeit als Außenseiter galt, der am Kunstgeschmack seiner Zeit vorbei produziert habe, weil seine Gestaltungen sich von denen seiner Zeitgenossen in zahlreichen Punkten unterschieden. Ansätze, ihn in den Kontext seiner Zeit zu stellen, konnten das Verständnis der Werke Rembrandts jedoch erheblich verbessern. ${ }^{31}$

Pausanias' Schrift wird auch in der neueren Forschung als eigene Gattung peri(h)egesis bezeichnet, ${ }^{32}$ allerdings unter anderen Prämissen als im späten 19. und frühen 20. Jahrhundert. Unter peri(h)egesis versteht man je nach fachspezifischer Ausrichtung Texte der (Kultur-) Geographie, ${ }^{33}$ der Reiseführer ${ }^{34}$ der Historiographie oder des Pilgerberichtes. ${ }^{35}$ Der Begriff di(h)egesis wurde von Reitz in Zusammenhang gebracht mit ,philosophisch geprägtem ethnographischen Schrifttum, das seine Wurzeln im historischen Epos und (antiker) wissenschaftlicher Literatur hat. ${ }^{\text {“36 }}$ Bowie und Elsner sehen die Periegese des Pausanias als eine Gattungsmischung. Bowie nimmt mehrere Vorbilder an, besonders prominent Herodot und außerdem Polemon von Ilion. ${ }^{37}$ Auch Hutton hat kürzlich die Diskussion wieder aufgenommen und die Frage, ob es eine Gattung Periegese gab, durch die Suche von Bezügen zu Fragmenten von anderen Periegesen zu lösen versucht. ${ }^{38}$ Er befasst sich in diesem Zusammenhang im Besonderen mit der bereits von Wilamowitz aufgestellten Vermutung, Pausanias habe Polemon von Ilion imitiert. ${ }^{39}$ Hutton kommt zu dem Ergebnis, dass es eine Gattung Periegese gab, die er aber anders definiert, als das in der älteren Forschung geschah: Pausanias hat nämlich nach Auffassung

31 Grohé, 1998, 9.

32 Von Reitz wurde der Terminus di(h)egesis (von diegeomai = erzählen, beschreiben) eingeführt: 1997, 511.

33 Schmalzriedt, 1980, 405; Hoheisel, 1985, 126; Chamoux, 1974, 83-90.

34 Casson, 1976, 352; Giebel, 1999, 205.

35 Elsner, 1992.

36 Reitz, 1997, 513.

37 Bowie, 2001, 25. Elsner, 2001, $7 \mathrm{f}$.

38 Hutton, 2005, $247 \mathrm{f}$.

39 Hutton, 2005, $251 \mathrm{f}$. Es erfolgt in diesem Zusammenhang auch der bereits in der älteren Forschung ausführlich dargestellte Verweis auf Ähnlichkeiten zwischen beiden im Hinblick auf Beschreibungstechnik und Themen (lógoi und theorémata) und, wie Hutton weiter vermutet, weiteren Autoren, die im Hellenismus schrieben. 
Huttons die Gattung weiterentwickelt und ein eigenes Genre kreiert; ${ }^{40}$ er führte nach Ansicht Huttons damit eine alte Tradition in neuer Form fort. ${ }^{41}$

\subsection{Lückenhaftigkeit und Selektion in der Periegese}

Mit der Kompilationsthese der älteren Forschung (s.u. Kapitel 1.5) war die Beobachtung einer bis heute nur gelegentlich noch diskutierten weiteren Eigentümlichkeit des Textes verbunden, nämlich die sogenannte Lückenhaftigkeit der Periegese. ${ }^{42}$ Ich würde eher von gezielten Auslassungen sprechen; dabei ist nicht das übergangene Monument wichtig, sondern vor allem das, wofür es steht. So ist z. B. bei Athen eine Parallele zwischen der weitgehenden Ausblendung der Peisistratidischen Monumente und der weitgehenden Ausblendung dieses historischen Abschnittes in der Periegese zu konstatieren. Das Einbringen so genannter Exkurse in der Periegese erfüllt einen komplementären Zweck, nämlich den Fokus auf bestimmte andere Dinge zu legen, die gerade nicht vor Ort sind. ${ }^{43}$

Pausanias weist mehrfach im Text darauf hin (z.B. 1,39,3; 3,11,1), dass er eine Auswahl in der Beschreibung der Monumente getroffen hat, wobei er jedoch die Auswahlkriterien nicht nennt, sondern nur sagt, dass es sich um 'Sehenswertes handelt, falls er nicht Monumente, Kultaitien u.ä. sogar ganz ausdrücklich übergeht. In der Beschreibung von Argos beispielsweise übergeht er absichtlich den Grund, weshalb man einen Ort Delta nennt, weil ihm die Erklärung dazu nicht zusagt, bei Nauplia übergeht er dezidiert das gleichwohl in aller Kürze erwähnte Kultaition, und zwar weil es ihm belanglos erscheint. ${ }^{44}$ Für das Verständnis der Periegese von erheblicher Bedeutung ist, dass es Auswahlkriterien gegeben hat, allerdings in der Mehrzahl absichtlich ungenannte. ${ }^{45}$ Hierin hat man m. E. ein Element der Verrätselung und damit der vom

40 Hutton, 2005, 256.

41 Hutton, 2005, $263 \mathrm{f}$.

42 Vgl. schon Gurlitt, 1890, 250: Die Lückenhaftigkeit der Periegese von Athen sei von allen, die sich mit Pausanias beschäftigt hatten, bemerkt und je nachdem beklagt oder gerügt worden. Die Annahme, dass Pausanias bewusst selektiert hat, vertritt in der neueren Forschung prononciert Akujärvi, 2005, 53 ff.

43 So z.B. Delphi (ausführlich dazu Kapitel 1.4).

44 S.u. das Kapitel >Die Beschreibung von Argos als Dekonstruktion eines Memory theaters.

45 Eine Übersicht von möglichen Kunstauswahlkriterien findet sich bei Kreilinger, 1997, $470 \mathrm{f}$. Sie geht von der von Pausanias selbst häufig gebrauchten Formulierung des 'Sehenswerten ‘ aus. Versuche, die Kriterien textimmanent zu bestimmen, sind von jeher problematisch gewesen und werden es auch in Zukunft zwangsläufig bleiben müssen. 
Leser erwarteten Entschlüsselung der jeweiligen Auswahlkriterien zu erblicken.

Die Beobachtung, dass die Periegese lückenhaft ist, wird nur noch sehr selten thematisiert und damit hermeneutisch kaum mehr nutzbar gemacht. Die Selektion wird, wenn wahrgenommen, zumeist lediglich als Mangel aufgefasst. In der neueren Forschung erscheinen Klassifizierungen der Lückenhaftigkeit und Selektion zuweilen in Relation zum narrativen Verlauf der Schilderungen des Pausanias. Die Beobachtung, dass Pausanias die (griechischen) Städte und ihre jeweilige Umgebung meist so vorstelle, dass Geschichte und Topographie in Verbindung mit der lokalen Mythologie und ortsüblichen Kulten als Einheit erscheinen, ${ }^{46}$ versieht z.B. Reitz mit dem Hinweis auf Defizite der Darstellungsweise. Diese sogenannten Defizite ergeben sich hier aus den Differenzen zum postulierten Genre des Reiseführers respektive Baedekers. So wird vermerkt, dass Pausanias ,zu wenig Interesse“ für Landschaft und $\mathrm{Na}$ turerscheinungen habe und beispielsweise die Stoa des Attalos in der Beschreibung der athenischen Agora „fehle.“47

Bereits Gurlitt untersuchte in seiner 1890 erschienenen Monographie unter anderem die allseits vermerkte Lückenhaftigkeit der Periegese von Athen; diese Lückenhaftigkeit wurde zu Ende des 19. Jahrhunderts von Pausaniaskritikern auf das Fehlen entsprechender Vorlagen zurückgeführt. Gurlitt, ein Gegner dieser Annahme, stellte das bei Pausanias in der Beschreibung von Athen Fehlende ausnahmslos zusammen. Er kam zu dem Ergebnis, dass Pausanias nicht nur von einer topographischen Schilderung der Stadt ganz absah und deshalb von Bergen, Straßen, Plätzen, Quartieren, Toren, Stadtmauern nur ausnahmsweise berichtete, sondern dass ganze Gruppen von Monumenten vollständig oder fast vollständig von Pausanias übergangen worden sind. ${ }^{48}$ Gurlitt erschien bemerkenswert, dass sich unter diesen Gruppen eine von topographisch zusammengehörigen Kulten und Gründungen befand, die westlich von einer das sogenannte Theseion mit dem Philopappos verbindenden Linie lagen $;^{49}$ eine andere von ihm als bemerkenswert ausgemachte Gruppe umfasste zeitlich zusammengehörige Bauten und Monumente, und zwar stammten diese von Peisistratos und den Peisistratiden, darunter so berühmte Stiftungen wie der Altar der zwölf Götter auf dem Markt. ${ }^{50}$

46 Reitz, 1997, 512; Casson, 1976, 357 f.

47 Reitz, 1997, 512. Ähnlich auch Casson, 1976, 359: Pausanias' Bemerkungen über exotische Vögel und andere Lebewesen werden als „Abschweifungen“ betrachtet, weiter wird von ihr kritisiert, dass die „endlosen mythologischen und historischen Exkurse oft das Übergewicht gegenüber dem eigentlichen Reiseführer zu haben scheinen."

48 Gurlitt, 1890, 251.

49 Gurlitt, 1890, 252.

50 Gurlitt, 1890, 253. 
Dass Pausanias nicht nur in Athen, sondern auch bei allen anderen von ihm beschriebenen Städten jeweils differente Selektionskriterien zugrunde gelegt hat, manche Dinge dabei übergangen, andere fokussiert hat, werde ich in Teil 2 zunächst anhand der in der Periegese geschilderten Biographien zeigen (Athen: Daidalos, Argos: Sakadas und Polyklet) und an seinen Beschreibungen der griechischen Mysterien vertiefen. In Teil 3 zeige ich die jeweils unterschiedlichen Funktionen von Lücken und Selektion an seiner Beschreibung an zwei kompletten Stadtbeschreibungen, Argos und Sparta. Es wird sich herausstellen, dass Pausanias von vornherein offenbar die Darstellung jeweils bestimmter Eigenschaften der Griechen im Sinn hatte, die durch seine Auswahl der Monumente für den Leser dann mehr oder minder nur noch belegt bzw. verifiziert werden.

\subsection{Verschiedenartigkeit der Bücher}

Dass die Bücher der Periegese unterschiedlich strukturiert sind und jeweils eigentümliche, d.h. individuelle Formen aufweisen, wird in der aktuellen Forschung $\mathrm{m}$. E. deshalb kaum mehr thematisiert und problematisiert, weil die Schlussfolgerungen, die man in der älteren Forschung aus der Verschiedenartigkeit der Bücher gezogen hatte, nur in einer rein pejorativen Wertung plausibel erschienen. Doch bleibt die Tatsache, dass die Bücher unterschiedliche Akzentsetzungen in der Darstellung haben, d. h. ihre >Architektur ‘ jeweils speziell ist. Der älteren Forschung erschien zu Recht die Unterschiedlichkeit der Bücher eklatant; doch hatten sich die Forscher, die sich mit diesem Phänomen eingehend beschäftigt und sie herausgearbeitet hatten, sich dann m. E. zu Unrecht - genötigt gesehen, lediglich verschiedenartige Vorlagen als Erklärung anzunehmen. ${ }^{51}$ Pausanias greift in jedem Buch bestimmte Themen auf, ${ }^{52}$ die z.T. allgemein-hellenisch, z. T. polisspezifisch sind. Diese Themen korrespondieren mit der jeweiligen Form der einzelnen Bücher, die deshalb unterschiedlich aufgebaut sind. Das hat als Effekt die Fokussierung auf signifikante Besonderheiten. Pausanias hat den unterschiedlichen Aufbau der Bücher mit System und Absicht betrieben und auch dementsprechend seine Referenztexte ausgewählt. Dem bekannten Phänomen der Verschiedenartigkeit der Bücher lege ich damit ein neues Erklärungsmodell zugrunde. Es

51 Im Einzelnen für: Athen, Olympia, Delphi, Lakedaimonien, Arkadien, Böotien, Achaia, Argolis, Sikyon, Korinth, Megara. Es handelt sich hier um Städte und Landschaften, für die anderweitige Abhandlungen existierten, die ihrerseits nicht oder nur wenig erhalten (Fragmente) sind oder nur indirekt bezeugt.

52 In Anlehnung an die Begriffsverwendung Thema bei Tigerstedt, Bd. 2, 1978, 224, der damit Topoi bezeichnet, unter denen diverse poleis bei Rednern und Historikern verhandelt werden. 
handelt sich um die Annahme, dass er mit einer visuellen Strategie der Fokussierung einerseits und der Überblendung (〉Exkurs $)$ andererseits gearbeitet hat. ${ }^{53}$

Auch Habicht hatte eine unterschiedliche "Gründlichkeit" in der Beschreibung vermerkt, ${ }^{54}$ was seiner Ansicht nach besonders bei Delphi negativ deutlich werde, wo Pausanias weniger ausführlich als in allen anderen Teilen seines Werkes beschrieben habe. Habicht mutmaßte, Pausanias hätten die Kräfte verlassen und er sei gestorben, bevor er alles überarbeiten konnte. Dass man hier ein wichtiges Phänomen vor sich hat, zu dessen Erklärung die Kompilationsthese nicht weiterhilft, zeigen en passent gemachte Beobachtungen von Jaquemin, ebenfalls zum 10. Buch respektive der Beschreibung Delphis. Ihr fiel auf, dass Pausanias im 10. Buch bei Delphi nur drei, zudem randständige Abhandlungen zu Delphi zitiert. ${ }^{55}$ Sie findet das verwunderlich, da es doch eine ganze Reihe von weiteren Werken zu Delphi gegeben habe, die in der Kaiserzeit auch noch greifbar gewesen sein müssen, aber bei Pausanias „fehlen“, d.h., soweit nachvollziehbar, nicht einmal indirekt benutzt wurden. ${ }^{56}$ Hieran knüpft sie die Frage, ob Pausanias dann nicht in Delphi seine Aufgabe als Perieget - diese versteht sie in dem Sinn, wie der Ausdruck bei Plutarch gebraucht ist, also als lokaler Führer vor Ort - verfehlt hat. ${ }^{57}$ Gerade an dieser Stelle lässt sich m. E. zeigen, dass Pausanias gar nicht die Absicht hatte, vollständig zu sein, sondern in seiner Beschreibung von Delphi möglicherweise ganz andere Aspekte im Vordergrund standen, als dessen ruhmvolle Vergangenheit zu schildern. Zudem muss man sich fragen, wieso er hier keine anderen Schriften herangezogen hat, obwohl doch so zahlreiche sgute Vorlagen zur Verfügung standen.

Jacquemins Feststellung, ${ }^{58}$ dass sich bei Pausanias nicht nur kein Hinweis auf Glanz oder Bedeutung der Pythien findet, sondern der Autor dieses Thema sogar ganz explizit ausblendet im Vergleich besonders zu Olympia, gibt einen m. E. aufschlussreichen Hinweis, wie diese eigentümliche Akzentuierung zu verstehen sein könnte: $:^{59}$ Pausanias charakterisiert Delphi nämlich

53 Die systematische Reflexion dieses Phänomens erfolgt in dem Kapitel zu Ekphrasis und Exegese (3.2.2).

54 Habicht, 1985, 18.

55 Geschichte Siziliens von Antiochos von Syrakus; das Buch über Cumae von Hyperokhos über die Sibyllen von Cumae; Schrift des Atthidographen Kleitodemos über athenische Sitten (Palmenprodigium).

56 Delphische Weihegeschenke in den Schriften des Theopompos, Anaxandridas, Polemon von Ilion, Alketas, Theodoros, Apollonios, Melisseus, Apollas von Pontos.

57 Jacquemin, 1991, $221 \mathrm{f}$.

58 Jacquemin, 1991, 229 f. wo sie die Amphiktyonie unter römischer Herrschaft zusammenfasst, die unter Augustus reorganisiert und von Nero besucht wurde.

59 Bendlin, 2006, 159 ff. behandelt das Mitte des 2. Jh. n. Chr. viel diskutierte Problem der Glaub- und Unglaubwürdigkeit von Orakeln und verweist darauf, dass das Pro- 
schon im 9. Buch (Boiotien) als vielberaubten Ort. ${ }^{60}$ Dieser Topos wird in 10,7,1 wieder aufgenommen. Pausanias schreibt dort: „Das Heiligtum in Delphi scheint von Anfang an von sehr vielen Menschen heimgesucht worden zu sein" und er belegt dies im Folgenden mit dem Verweis auf eine lange Tradition der Beraubungen Delphis: Der euboiische Räuber, das Volk der Phlegyer, Pyrrhos, das Heer des Xerxes, die Phoker, Galater und schließlich Nero. Ich möchte in diesem Zusammenhang auch darauf hinweisen, dass die Weihegeschenke in Delphi, von denen Pausanias berichtet, ausschließlich aus Kriegskontexten stammen. Sieht man sich den Gesamtaufbau des 10. Buches (Phokis) an, so fällt auf, dass es überhaupt keine Geschichte der Delpher gibt, sondern insgesamt vier außergewöhnlich lange lógoi, so genannte Exkurse: Delphi mit Schilderung des Heiligen Krieges, Sardinien, ${ }^{61}$ den Galatereinfall und die Lesche der Knidier. Jeder lógos fokussiert auf unterschiedliche Weise das Thema Krieg.

Die daraus folgende These ist also, dass die Bücher unterschiedlich aufgebaut sind, weil jeweils ganz bestimmte Besonderheiten vom Autor betont werden sollen. Ich werde diese Annahme anhand meiner Beschreibungsanalyse weiter unten in den Kapiteln über Argos und Sparta ausführlich erläutern und belegen. Das in der Periegese entfaltete, differenzierte Geschichtsbild und die daraus resultierende Verschiedenartigkeit der Bücher laufen demnach synchron. So wird bei einigen Städten die Prosperität durch die Auswahl der Monumente herausgestellt, bei anderen Städten werden ganz andere Aspekte hervorgehoben. So ist in der Beschreibung des Pausanias Athen zu neuer Blüte gelangt, ebenso wie namentlich Korinth, Patrai, Pallantion und Mantineia (mit jeweils sehr unterschiedlichen Begründungen in der Periegese). Argos wird, obwohl es im 2. Jh. n. Chr. eine baulich prosperierende Stadt nach den archäologischen Befunden war, von Pausanias geradezu diskreditierend dargestellt, was die Auswahl des Sehenswerten angeht. Möglicherweise spielt bei seiner Darstellungswiese eine Rolle, dass Argos in der Kaiserzeit Hauptkonkurrentin von Athen war, wie Pausanias selber schreibt, wobei er sich explizit auf das Alter und die von den Göttern erhaltenen Ehren bezieht $(1,14,2)$.

blem, dass Orakel unwahr oder obskur sind, von Pausanias diskutiert und besonders diskreditierend auf Delphi angewendet werde.

60 Und zwar bereits in 9,36,2: Die Phlegyer fallen von den Orchomeniern ,aus Dummheit oder Frechheit" ab, plündern oder berauben ihre Nachbarn und unternehmen schließlich sogar einen Raubzug zum Heiligtum in Delphi.

61 Man kann diesen sogenannten Exkurs als Wiedergutmachungsbericht lesen. Nero hat Weihestatuen aus Delphi entfernt, aber: Nero gibt den Griechen auch die Freiheit zurück und den Römern dafür wiederum Sardinien. Daher könnte sich erklären, dass der Sardinienexkurs im 10. Buch steht: Nero hat genommen und gegeben. 


\section{5 'Kompilation}

Welche Implikationen die so genannte Kompilation als offene und versteckte Verwendung anderer Autoren bei Pausanias hat, kann weder auf der Basis eines einzigen Autoren noch für alle von ihm zitierten Autoren gleichmäßig zutreffend beantwortet werden. Von der Verwendung des literaturwissenschaftlichen Begriffes Intertextualität sehe ich hier ab, weil er kein adäquates Homonym zu den Konzepten der Kompilation und Buntschriftstellerei ist, so wie sie im 19. Jahrhundert verstanden wurden. Helbig hat als Charakteristikum der Intertextualität die Ermittlung von Markierungsverfahren in literarischen Texten genannt, die fundierte Rückschlüsse auf intendierte Leserrollen erlaubten. Dieser Aspekt ist hilfreich für das Verständnis von Pausanias' Verwendung der Homerischen Epen, nicht jedoch für die Verwendung anderer Autoren durch Pausanias wie z.B. Herodot, Thukydides, Polybios oder Apollodor und Akusilaos. ${ }^{62}$ Zwar gibt es in diesen Fällen zumeist die von Helbig genannte, ,gewollte Differenzierung zwischen alludierenden und nicht-alludierenden Textsegmenten", doch bietet sie in diesen Fällen keine Ansatzpunkte zum jeweiligen Zitatverständnis. ${ }^{63}$ Es handelt sich gewissermaBen um das falsche Stichwort für ein bedeutsames und auffälliges Phänomen. Pausanias ist, zumal in der Kaiserzeit, nicht nur nicht der einzige Autor, der andere Texte ‘kompilatorisch benutzt (u.a. Clemens von Alexandrien und Macrobius), sondern das Phänomen einer prononciert zitathaften Montage wird beispielsweise auch für die Architektur der Spätantike beobachtet (z.B. Konstantinsbogen in Rom). Es stellt sich somit die Frage, was diese Technik generell über den Umgang einer Epoche mit Fragmenten aus anderen Texten oder aber auch Gebäuden auszusagen vermag. Diese komplexe Frage kann in der vorliegenden Untersuchung freilich nicht beantwortet werden. Ich werde nur die Benutzung anderer Autoren und Werke bei Pausanias in zwei Kapiteln ausführlich behandeln (3.3 und 3.4) und dabei besonders der unterschiedlichen Verwendung von Homer und Apollodor nachgehen. Im Folgenden beschränke ich mich zunächst darauf, die Frage nach dem Phänomen der Kompilation in der Periegese in ihrer forschungsgeschichtlichen Relevanz und anhand des Beispiels des 4. Buches (Messenien) darzustellen.

Der ganze Bereich der von der Forschung des 19. Jahrhunderts problematisierten und erkannten Verwendung anderer Autoren und Schriftzeugnisse durch Pausanias wird, abgesehen von den in der Periegese zitierten Inschriften, in der neueren Pausaniasforschung nicht mehr thematisiert. In der älteren Forschung des 19. Jahrhunderts stand hier vor allem die literarische Qualität

$62 \mathrm{Zu}$ Pausanias' Transformation von Positionen des Thukydides, besonders im 3. Buch (Sparta), siehe jetzt Ellinger, 2005, $30 \mathrm{ff}$.

63 Helbig, 1996, 12. 
der Periegese zur Debatte. Sie wurde wegen mangelnder Originalität kritisiert und umgekehrt aufgrund der dadurch durchscheinenden Belesenheit des Pausanias, der aus so vielen Werken sein eigenes zusammengesetzt zu haben schien, verteidigt. Gurlitt sprach gar von einem „,musivischen Zusammenar-

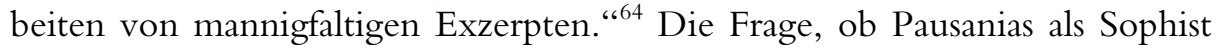
anzusehen ist, wurde daher in der älteren philologischen Forschung nicht allein zusammen mit der Frage nach einem fehlenden Proöm diskutiert, sondern vielmehr mit der Art und Weise, wie Pausanias andere Autoren benutzte.

Den Hintergrund der diesbezüglichen, oft polemisch gefärbten Argumentationen bildete die sogenannte Pausaniasfrage. Es handelt sich um den Streit darüber, ob Pausanias die von ihm beschriebenen Monumente selbst gesehen oder die Autopsie unter Verwendung existierender Texte nur ,,vorgetäuscht" hatte. ${ }^{65}$ Letzteres traute man vor allem einem Vertreter der Zweiten Sophistik zu, ersteres einem seriösen und ernsthaften Forscher. ${ }^{66}$ Dass Pausanias keinesfalls immer versteckt zitiert oder sich unausgesprochen auf andere Werke beruft, war dabei durchaus auch aufgefallen, aber als eine halbherzige Konzession aufgefasst worden. Man nahm an, er habe zumindest ab und zu gesagt, von wem er abschreibe, um sich wenigstens einen seriösen Anstrich zu geben. So tut er dies ganz ausführlich zu Beginn des 4. Buches (Messenien, $4,6,1-4) .{ }^{67}$ Pausanias erörtert und begründet in dieser Stelle, dass er seine

64 Gurlitt, 1890, 28.

65 Zusammenfassung und Überblick bei Habicht, 1985, 170 f.; Robert, 1909, 1.

66 Dass eine solche Dichotomie problematisch ist, war schon Pasquali, 1913, bes. 194 und Robert, 1909, 68 passim bewusst.

67 4,6,1: „Diesen Krieg der Messenier hat Rhianos aus Bene in seinem Epos dichterisch dargestellt und Myron aus Priene; Myrons Darstellung ist aber in Prosa geschrieben. (2) Eine zusammenhängende Darstellung des Ganzen vom Anfang bis zum Ende des Krieges hat aber keiner von beiden gegeben, sondern nur den Teil, der ihm gefiel; der eine hat die Eroberung von Ampheia und die anschließenden Ereignisse dargestellt nicht weiter als bis zum Tode des Aristodemos, Rhianos aber hat diesen ersten Krieg überhaupt nicht berührt, sondern nur, was später den Messeniern zustieß, die von den Lakedaimoniern abgefallen waren, und auch das nicht alles beschrieben, sondern nur die Geschehnisse nach der Schlacht, die sie an dem sogenannten Grossen Graben lieferten. (3) Den einen einzigartigen Messenier, dessentwegen ich diesen ganzen Exkurs über Rhianos und Myron mache, den Aristomenes, der als erster und ganz besonders den messenischen Namen berühmt machte, diesen Mann hat der Prieneer in die Darstellung eingeführt, und im Epos des Rhianos ist Aristomenes nicht weniger glanzvoll als Achill bei Homer in der Ilias. Da sie nun etwas derart Verschiedenes sagen, blieb mir nur übrig, mich der einen der beiden Erzählungen anzuschließen und nicht beiden zugleich, und zwar scheint mir Rhianos' Dichtung über das Zeitalter des Aristomenes glaubwürdiger zu sein. (4) Dass Myron sich nicht darum bekümmert, wenn er Falsches und Unwahrscheinliches zu erzählen scheint, kann man auch sonst erkennen und in diesem seinem messenischen Buch besonders. Er hat nämlich erzählt, 
eigene Darstellung nach der Art des Trojanischen Krieges präsentiert, dem er den Messenischen wegen der Ähnlichkeit der Helden Achill und Aristomenes angleichen will. Darauf soll demnach der Leser für die folgende Lektüre achten. Zugleich ist Pausanias' Begründung dem Anspruch nach der einer verbesserten Geschichtsschreibung. Auch dies wurde von Kalkmann zutreffend beobachtet, aber so bewertet, dass Pausanias hier nur einen Vorwand gibt, um seine Vorlagen ,auszuschreiben. “68

Der Althistoriker Schwartz hatte seinerzeit herausgearbeitet, dass Pausanias mit dem Buch über Messenien eine ganz der Sichtweise der Kaiserzeit entsprechende Auffassung und Deutung der messenischen Geschichte dargestellt hat:

„Durchweg schreckt die Tendenz, die Messenier zu unschuldigen, makellosen Helden zu machen, vor geschmacklosen Erfindungen nicht zurück. Die Schlachtgemälde des ersten Königs sind Pfuscherkopien nach den Klassikern Thukydides und Xenophon: die Eroberung von Hira, die Schlacht am Ebermal haben manches, was an Thukydides Berichte von dem Durchbruch der Plataeer durch die peloponnesischen Verschanzungen und der Schlacht bei Mantineia erinnert, der große Graben scheint aus der Anabasis Xenophons zu stammen, die Gründungsgeschichte von Zankle ist nach Herodot und Thukydides zusammengeklittert.

Diese „Geschichtsklitterung“ traute er, wie die meisten Forscher seiner Zeit, Pausanias nicht einmal selbst zu, sondern meinte, Pausanias habe seine Version aus einer verlorenen frühkaiserzeitlichen Quelle übernommen und dann nur noch entsprechend stilistisch überarbeitet. Auch Pasquali folgerte aus der Benutzung älterer Geschichtswerke zu Messenien durch Pausanias lediglich:

„Die Historiker des Hellenismus mögen ihm für seine Mühen sehr dankbar sein, wie die Historiker Altgriechenlands dafür, dass er in seiner Geschichte Messeniens ein Werk der Kaiserzeit benutzt hat, in dem das historische Epos des Rhianos von Bene in Prosa umgesetzt war. ${ }^{"}{ }^{70}$

Weder Pasquali noch zeitnah schreibende Philologen zogen in Betracht, dass der Wechsel zwischen expliziter und impliziter Bezugnahme absichtsvoll und damit funktional gewesen sein könnte. Auch Kalkmann hatte Eigentümlichkeiten insbesondere des 4. Buches (Messenien) analysiert. Wie Pasquali und andere führte er dies auf die Kompilation und ihre Folgen zurück:

„Ganz unberücksichtigt blieb das vierte Messenien behandelnde Buch: Es sind neunundzwanzig Kapitel Geschichte und sieben Periegesen. In Folge der breiten

wie Aristomenes den lakedaimonischen König Theopompos kurz vor dem Ende des Aristodemos tötete, und doch wissen wir, dass Theopompos weder in einer Schlacht noch sonst vor der Beendigung des Krieges gestorben ist."

68 Kalkmann, 1886, 155.

69 Schwartz, 1899, $457 \mathrm{f}$.

70 Pasquali, 1913, 193. 
Behandlung der Geschichte nähern sich die Messeniaka ungefähr an Umfang anderen Abschnitten; so verbreitert Pausanias auch die Achaika durch eine Einlage über die ionischen Städte, ihre Geschichte und Sehenswürdigkeiten. Wer den Abschnitt über die Geschichte Messeniens, der für moderne Geschichtsforschung manche Lücken dankenswert ergänzt, aus einem tieferen Interesse für die Geschicke des armen Landes entstanden glaubt, der muss den Beweis bringen, dass die Periegese gedrängt behandelt ist. Vielmehr hat es hier an Stoff oder besser an ergiebigen Quellen gefehlt: die Darstellung strotzt von beiläufigen Ausführungen und langatmigen überflüssigen Exkursen mythologischen naturgeschichtlichen ethnologischen paradoxologischen historischen Inhalts, lässt aber auf der anderen Seite Aufklärungen über die wichtigsten Altertümer vermissen; wo das Hierothysion eigentlich war, erfahren wir nicht, nichts näheres z.B. über die Artemis Paidotrophos, über den Apollo Korydos. Von Messeniaka haben wir außer von denjenigen des Myron und Rhian, die wesentlich historisch gewesen zu sein scheinen, und den poetischen eines Alexandriners Aischylos keine Kunde. “71

All dies scheint Kalkmann lediglich als Argument für „Zusammenschreiberei“ und Ausrichtung des Werkes an verfügbaren Quellenvorlagen. In der neueren Forschung haben $\mathrm{m}$. W. nur noch Habicht und Dihle das Phänomen der Kompilation beachtet, wenn auch nicht eingehend. Habicht hatte das Phänomen, dass Pausanias andere Autoren z. T. offen, weitaus häufiger aber versteckt zitiert, im Hinblick auf die ältere Forschung diplomatisch gelöst. Pausanias schreibe nicht vorhandene Quellen aus, sondern bringe aus dem Gedächtnis zahlreiche Zitate. ${ }^{72}$ Auch Dihle weist als einer der wenigen modernen Forscher darauf hin, dass Pausanias unbestreitbar viele schriftliche Quellen, insbesondere für die langen Ausführungen zur Geschichte und Mythologie benutzt habe. Er setzt dies in impliziter Anknüpfung an die ältere Forschungsdiskussion in Beziehung zu der Frage, ob Pausanias denn das von ihm beschriebene Griechenland auch tatsächlich bereiste und vermerkt, dass die zahllosen präzisen Angaben zur Topographie eigentlich nur erklärlich seien, wenn man Autopsie beim Autor voraussetze. Er deutet diesen Befund dahingehend, dass Pausanias sich als Leser den literarisch Gebildeten vorgestellt habe und die Periegese also kein antiker Baedeker sei. ${ }^{73}$

71 Kalkmann, 1886, 154 mit Anm. 1.

72 Habicht, 1985, 96. Vgl. auch 139: Da für Habicht die Literatur des 2. Jh. leere Hervorbringung ist, war er der Ansicht, Etiketten wie Sophist und Buntschriftsteller täten dem Pausanias unrecht und seien glücklicherweise kaum noch in Gebrauch.

73 Dihle, 1989, 260. 


\subsection{Stilmischung}

Neben der Buntschriftstellerei war ein eigener Untersuchungsgegenstand der Forschungen des 19. Jahrhundert zu >Pausanias als Sophist s seine Sprache und sein Stil. Hier standen sich die Auffassungen gegenüber, dass Pausanias reinfach « geschrieben habe, um sachlich und unprätentiös zu wirken oder aber sehr stilbewusst, um rhetorische Bildung zu demonstrieren: der Variantenreichtum in der Sprache sei ihm wichtiger gewesen als akkurate Beschreibung. Die erste umfängliche Untersuchung zum Thema erschien 1907 und stammt von Engeli, der als Hauptmerkmal die oratio variata als gezieltes Abweichen von der natürlichen Ausdrucksweise (Verwendung von Synonymen, Wechsel der Konstruktion) analysierte. Engeli kam zu dem Ergebnis, dass Pausanias dadurch eine größtmögliche Anschaulichkeit der beschriebenen Objekte und Handlungen erzeugte.

Der Forschungsansatz `Stilmischungく wird bis heute immer wieder aufgegriffen, und zwar deshalb, weil sich nicht von der Hand weisen lässt, dass es sich bei Pausanias' Schreib- und Ausdrucksweise, der Wortwahl, der Syntax etc. um einen philologisch nachweislich `konstruiert einfachen Stil handelt. ${ }^{74}$ Zuletzt erneut bestätigt hat dies die aus dem Jahr 1999 stammende Untersuchung von Akujärvi. Auch sie kommt zu dem Ergebnis, dass Pausanias als stilbewusster Autor angesehen werden muss und daher die Annahme sehr plausibel erscheint, dass er sein Werk sehr sorgfältig plante. ${ }^{75}$ Die Schlussfolgerung, dass Pausanias sein Werk sorgfältig geplant hat, bestätigt sich vor allem in seiner Anordnung und Auswahl der lógoi und theorémata. Neuere Untersuchungen zur Stilmischung sind vielfach nicht bewusste Wiederholungen der älteren Pausaniasforschung und führen zu ähnlichen Ergebnissen. ${ }^{76}$ Mit Engeli

74 Nach Ansicht von Engeli, 1907, 51, hatte Pausanias sich darüber hinaus diverser weiterer Stilmittel bedient, um zu kaschieren, dass er aus verschiedenen Vorlagen zusammengeschrieben hatte. Die nächste monographische Abhandlung zu diesem Thema erschien 1976 und wurde von Strid verfasst, der in der Sprach- und Stilanalyse zu ähnlichen Ergebnissen kommt wie Engeli und die Engeli nachfolgenden Untersuchungen zum Stil, wie etwa Pasquali, 1913, bes. 212 ff. Strid war zu der eigentümlichen Ansicht gelangt, dass „Pausanias in der stilistischen Bewältigung des Stoffes seine Hauptaufgabe sah. Er wollte sein Werk literarisch interessant und anziehend machen, vielleicht hat er sich, wie Regenbogen es tut, gefragt, wer eine kahle Periegese in zehn Büchern lesen möchte" (Strid, 1976, 102).

75 Akujärvi, 1999, 9. Siehe jetzt auch mit den gleichen Beobachtungen Hutton, 2005, 8 f.

76 Hutton 2005, 230 f. Hutton diskutiert den Stil gegen Strid, der sich gegen die Imitation des Hegesias ausgesprochen hatte, wie vor ihm schon Pasquali gegenüber Robert. Hutton plädiert in Unkenntnis dieser Debatte nun doch wieder für Hegesias, wie vor ihm aus den gleichen Gründen Bowie, 2001, 26. Auf das Phänomen solcher unbewussten Wiederholungen zur Analyse und Diskussion des Sprachstils macht auch Whittaker 2000/2001, 125 aufmerksam. Hier stehen sich die Auffassungen gegenüber, 
und Akujärvi soll hier lediglich festgehalten werden, dass Pausanias' Stil zugleich sachlich, rhetorisch anspruchsvoll und anschaulich war, und zwar, um gelehrte Objektivität zu demonstrieren.

\subsection{Neuere Forschungspositionen}

Das verstärkte Interesse an Pausanias verdankt sich vor allem dem derzeitigen Interesse der altertumskundlichen Forschung an Griechenland unter römischer Herrschaft: Es wird angenommen, dass in der Periegese die Sichtweise eines Griechen auf Griechenland reflektiert ist, der unter der römischen Herrschaft lebte. $^{77}$

Die Tatsache, dass zu Pausanias' Periegese kein Proöm und kein Schluss und damit keine Selbstpositionierung des Autors gegenüber seinem Text existiert, hat unterschiedliche Herangehensweisen in der Forschung bewirkt: Zum einen die bereits besprochenen unvermeidlichen Spekulationen über die Textgattung vorwiegend in der älteren Forschung; zum anderen Versuche in der neueren Forschung, den Text inhaltlich und systematisch, d.h. vorwiegend von den beschriebenen Objekten her und durch die Erzählweise des Autors zu erschließen, womit Fragen nach einer `Gattung Periegese` weitgehend ausgeblendet werden.

\subsubsection{Pilgerbericht}

Es geht bei der kritischen Diskussion der Frage, ob Pausanias einen Pilgerbericht verfasst hat, hauptsächlich um das Problem, ob die Verwendung des Begriffes >Pilger und >Pilgerwesen ist. Dillon hat in seiner Monographie zu Pilgern und Pilgerwesen im antiken Griechenland (1997) das Reisen zu Kultstätten seit etwa dem 5. Jh. v. Chr. als festen Bestandteil der griechischen Religion untersucht. Er kommt unter anderem zu dem Ergebnis, dass, während die vor allem politisch wichtigen Reisen (theoria) zu panhellenischen Festen und Heiligtümern der klassischen und hellenistischen Zeit in römischer Zeit zurückgehen, Fahrten zu Orakeln und Einweihungsstätten quantitativ kaum nachlassen. Dillon verzeichnet

dass Pausanias einfach geschrieben habe, um sachlich und unprätentiös zu wirken oder sehr stilbewusst, um rhetorische Bildung zu demonstrieren. Der Variantenreichtum in der Sprache sei ihm wichtiger als akkurate Beschreibung. Dazu ist anzumerken, dass es auch in den Stiluntersuchungen durchaus unterschiedliche Bewertungen gibt. Engeli beispielsweise hat herausgearbeitet, dass Pausanias gerade durch seine Wortwahl auBerordentlich akkurat ist.

77 Whittaker, 2000-2001, 124. Sie nennt außerdem als Auslöser die Pausaniasmonographie von Habicht. 
damit einen Umschwung von der politisch oder militärisch motivierten Konsultation städtischer Abordnungen zur vorwiegend an individuellen Fragen und Problemen interessierten privaten Klientel, der einhergeht mit einem Wechsel in der Prominenz von Orakel- und Einweihungsstätten und der Etablierung neuer Zentren. Auf die hieraus resultierenden Schwierigkeiten hat Graf in seiner Rezension hingewiesen: ${ }^{78}$ Es gehe im Wesentlichen um die Frage, wie man mit hermeneutischen Begriffen in der Religionswissenschaft umgeht, d.h. welchen Stellenwert man ihnen im Verhältnis und im Vergleich zu unter anderem auch philologischen Methoden zumessen kann und muss. Graf hat dies am Begriff des Pilgerwesens exemplifiziert und gefragt, ob der aus dem Christentum entnommene Begriff und das Phänomen Pilgerwesen adäquat sei, um darunter verschiedene Epochen der griechischen Religionsgeschichte respektive das Phänomen „Reisen zu Kultstätten“ nicht nur zu subsumieren, sondern auch, um ein neues Paradigma zum Verständnis griechischer Religion zu etablieren. Graf forderte, dass man dezidiert textkritisch an das verwendete Material und gewählte Thema herangehen müsse.

Das Eintreffen zu religiösen Festen ist nun etwas, um das Pausanias sich nur gelegentlich bemüht hat, das aber nicht, wie für Verfasser von Wallfahrtsberichten signifikant, Ziel und Ausgangspunkt seiner Unternehmung war. ${ }^{79}$ Eine Ähnlichkeit zu Pilger- oder Wallfahrtsberichten ist in der Periegese auf den imaginierten stationären Verlauf der Reise und die Schilderung ortsüblicher religiöser Praktiken begrenzt. Erwähnt werden von Pausanias zwar zahlreiche Feste in den Städten, aber durchweg wird nicht angegeben, wann die Feste stattfinden. Die Angaben beschränken sich auf den Namen des jeweiligen Festes, Festbeschreibungen gibt es nur gelegentlich. ${ }^{80}$ Dabei ist in der Regel auch nicht unmittelbar ersichtlich, weshalb ein Fest beschrieben wird und eine Reihe anderer nicht, dies muss der Leser selbst erschließen. Pausanias vermerkt zudem verschiedentlich, dass er zum Fest nicht vor Ort war, so z. B. im 8. Buch (Arkadien) in Phigalia, beim Artemisfest. ${ }^{81}$ Es ist in der Beschreibung unver-

78 Graf, 2002, $193 \mathrm{ff}$.

79 Herbers, 1991, 26.

80 So in dem oben im Text zitierten Beispiel mit markierter Autopsie seiner Anwesenheit und ausführlicher Festbeschreibung der Artemis Laphria in Patrai (7,18,11 ff.). Markierte Autopsie und Anwesenheit auch beim Fest der Dindymenischen Mutter in der Nähe Thebens $(9,25,3)$.

81 8,41,5: „Das Volk von Phigalia glaubt, das Eurynome ein Beiname der Artemis sei; diejenigen aber von ihnen, die alte Schriften zur Hand genommen haben, sagen, Eurynome sei eine Tochter des Okeanos, deren auch Homer in der Ilias Erwähnung tat, dass sie mit Thetis den Hephaistos aufnahm. Jedes Jahr am selben Tag öffnen sie das Heiligtum der Eurynome; die übrige Zeit dürfen sie es nicht öffnen. (6) Dann opfern sie auch von Staats wegen und privat. Ich war nicht gerade zur Zeit des Festes gekommen und habe daher auch das Bild der Eurynome nicht gesehen. Von den Phigaleern hörte ich, dass goldene Ketten das Holzbild zusammenhalten, und dass es bis zu den Hüften das Bild einer 
kennbar, dass Pausanias diese Artemis bzw. ihre Gestalt für obskur und kurios hält: Man verpasst nichts Wesentliches, wenn man das Bildnis nicht sieht bzw. nicht zum Fest kommt, wird dem Leser suggeriert; in diesem Fall hätte man dann sogar das Kuriosum eines partiellen Anti-Pilgerberichtes vor sich, so z. B. auch in 6,26,1 mit markierter Autopsie. Auch hier scheint es sich wieder um ein nicht übermäßig berühmtes bzw. sehenswertes Fest zu handeln, da nur gelegentlich und vereinzelt überhaupt Fremde aus diesem Anlass gekommen zu sein scheinen:

„Von den Göttern verehren die Eleer Dionysos besonders und sagen, der Gott besuche sie am Fest der Thyien. Der Platz, wo sie das Thyia genannte Fest feiern, ist gegen acht Stadien von der Stadt entfernt. Die Priester bringen drei Kessel in ein Gebäude und stellen sie leer hin im Beisein der Bürger und Fremder, wenn gerade welche anwesend sind; dann bringen die Priester selbst, und wer von den übrigen Lust hat, ihre Siegel an den Türen des Gebäudes an. (2) Am folgenden Tage können sie die Siegel prüfen, gehen in das Gebäude hinein und finden die Kessel mit Wein gefüllt. Die angesehensten Leute von den Eleern und mit ihnen auch Fremde schwuren mir, dass sich das wie berichtet verhalte, da ich selber nicht zur Festzeit gekommen war."

Es stellt sich überdies die Frage, was man mit den zahlreichen historiographischen, geographischen und ethnographischen Passagen der Periegese tut, die nicht in die Form eines Pilgerberichtes passen. Wegstreckenbeschreibungen gibt es zwar durchgehend, aber keinerlei Hinweise auf für Pilgerberichte wesentliche Angaben zu Quartieren und Unterkünften. ${ }^{82}$ So muss man sich eher umgekehrt fragen, was die Funktion der topographischen Angaben im Text ist, wenn die Periegese nicht als Pilgerbericht dienen sollte. Ich möchte mich daher der Meinung Grafs anschließen, ${ }^{83}$ dass Konzepte von Pilger und Pilgerreise in der Analyse eines Werkes wie das des Pausanias sowie anderer, zeitgleich schreibender Autoren, die Reisen im Kontext von Religion unternahmen, kaum anwendbar sind. ${ }^{84}$

Elsner hat demgegenüber ein weit differenzierteres Konzept von Pausanias als Pilger entwickelt. Er vertrat die Ansicht, dass Pausanias als Pilger einen

Frau sei, darunter ein Fisch. Der Fisch könnte wohl ein Kennzeichen dafür sein, dass sie eine Tochter des Okeanos ist und mit Thetis zusammen in der Tiefe des Meeres wohnt; für Artemis ist es unmöglich, dass sie mit wahrscheinlicher Begründung eine solche Gestalt haben könnte."

82 Herbers, 1991, $24 \mathrm{f}$.

83 Graf, 2002, $195 \mathrm{f}$.

84 Rutherford, 2001, $41 \mathrm{f}$. hat die Periegese als Pilgerbericht bezeichnet und in Zusammenhang mit der Pilgerkultur unter den Antoninen gebracht. Pausanias sei ein für die Zeit typischen Pilger, Tourist und Pepaideumenos. Hutton, 2005, 8 übernimmt den Begriff >Pilger für seine Untersuchung unter Verweis darauf, dass Pausanias an Kultgeschehen partizipiert hat, dies mit Referenz auf das Konzept Elsners. Differenziert zu religiös motivierten Reisen im Kontext der griechischen Kultur Schlesier 2000, bes. $136 \mathrm{f}$. (Orakelkonsultation und Einweihung in Mysterien). 
Führer durch die griechische religiöse Identität als Form des Widerstandes gegen die Realitäten der römischen Herrschaft biete. Pausanias versuche mittels der Religion die historische Realität zu transzendieren. ${ }^{85}$ Dies leitet er vor allem daraus ab, dass Pausanias' Interesse an Religion beinahe „obsessiv“ sei. Das ist es in der Tat, aber m. E. aus anderen Gründen, als Elsner sie vermutet. Ebenfalls nicht von der Hand zu weisen ist Elsners Beobachtung, dass Pausanias seine Frömmigkeit u.a. dadurch dokumentiert, dass er in zahlreiche Mysterien eingeweiht war. ${ }^{86}$ Ich werde demgegenüber in dem Kapitel über Pausanias' Beschreibung der griechischen Mysterien (2.3.5) darlegen, dass es sich hierbei um die Einnahme einer Sprecherrolle (frommer Pepaideumenos) handelt, aus der heraus die griechischen Mysterien einer differenzierten Wertung unterzogen werden, die zu einer Hierarchisierung fuihrt. Es erscheint deshalb fraglich, ob Pausanias' Reisen als vorwiegend religiös motiviert anzusehen sind, ebenso wie die Routen, die er gewählt hat. ${ }^{87}$

\subsection{2 > Theater of memory der Griechen}

Die Annahme, dass die Periegese primär der religiösen Erinnerung dienen könnte, wird in der modernen Forschung besonders prominent vertreten. Als Manifestationen eines religiösen Gedächtnisses im Werk des Pausanias werden die zahlreich im Werk beschriebenen und erwähnten sakralen Monumente, lokalen Mythen im Kontext von Orts- und Landschaftsbeschreibungen sowie die Schilderung kultischer Handlungen angesehen. ${ }^{88}$ Von neueren Arbeiten, die das Thema $/$ Religion und Erinnerung bei Pausanias untersuchen, sind neben Auffarth, der die Periegese als Zeugnis für eine aus der klassischen griechischen Religion abgeleitete retrospektiv begründete Identität interpretierte ${ }^{89}$ besonders die Arbeiten Alcocks und Elsners zu nennen. In der vorliegenden Untersuchung wird demgegenüber die Ansicht vertreten, dass diese religiös-mythologischen und historischen Vergangenheitsbezüge in der Perie-

85 Elsner, 1992, 5.

86 Elsner, 1992, 8.

87 Elsner, 1992, 11.

88 Etwa im Sinne A. Assmanns, 1994, 39, als allgemeines ‘Gedächtnis der Ortes: „Die Praxis der Kulte befestigt die Aura heiliger Orte, mythische Erzählungen fundieren sakrale Landschaften, die historische Erzählung stützt Gedächtnisorte, das pietätvolle Andenken an Tote stabilisiert Gedenkorte. Kein Gedächtnis der Orte, so könnte man dieses Ergebnis zusammenfassen, ohne bestimmte Formen einer kulturellen Mnemotechnik." Dieser Ansatz ist von Goldmann, 1991, 154 übernommen worden. Er hob hervor, dass Pausanias großen Wert auf den Wortlaut von Lokaltraditionen lege, weil Erinnerungen ortsgebunden blieben, sie den Einheimischen gehören und im kollektiven Gedächtnis einer Landschaft verankert seien.

89 Auffarth, 1997 am Beispiel Patrai. 
gese Voraussetzung für eine differenzierende Hierarchisierung und Wertung der Städte sind, nicht ihr Ziel. ${ }^{90}$

Alcock sieht in dem von ihr als obsessiv gewerteten Vergangenheitsbezug der griechischen Städte besonders in der Kaiserzeit eine Reaktion auf die römische Herrschaft. ${ }^{91}$ Dabei geht sie davon aus, dass die griechischen Städte eine kollektive und weitgehend konsensuale Identität besaßen und sich folglich in gleicher Weise negativ von der römischen Herrschaft betroffen sahen, ${ }^{92}$ der sie mit einer intensiven Rückschau (Erinnerungsarbeit) und damit Fixierung auf die eigene Religion, Mythologie und Geschichte begegneten. Als Medien setzten die Griechen hierbei Architektur, Landschaft und Archäologie (Monumente) ein, mit denen sie ihre Städte zu Schauplätzen der Erinnerung gestalteten (theater of memory $<$ ). ${ }^{93}$ Unter diesem Gesichtspunkt versteht Alcock auch Pausanias' Beschreibung Griechenlands als Ausdruck dieser griechischen Erinnerungskultur, ${ }^{94}$ was ihn in die Nähe zu Vertretern Zweiten Sophistik bringt. Die Feststellung von Alcock, der zufolge Pausanias ein weitgehend in Ruinen liegendes Griechenland beschreibt, ${ }^{95}$ scheint mir zu pauschal, denn es werden in der Periegese sowohl einerseits intakte Städte beschrieben (z.B. Athen, Korinth, Argos, Sparta) als auch die Ursachen der Zerstörungen immer angegeben. Pausanias hat gelegentlich auch Ruinen absichtlich ausgesucht, um an ihrem Zustandekommen etwas je besonderes zu zeigen. So etwa werden Ruinenstädte in der Umgebung von Argos als von den Argivern mutwillig zerstört beschrieben, der Niedergang von Megalopolis hingegen als vom Schicksal zum Scheitern verurteilte griechische Hybris. ${ }^{96}$ Alcock bewertet die Tatsache, dass Pausanias vielfach lokale Überlieferungen negiert oder es besser weiß, als Geburtsstunde einer dominanten und ansatz-

90 Vgl. Schlesier, 2000, 144. Sie verweist darauf, dass die griechische Kultur eine „durchgängig religiöse Kultur war, dass aber die spezifische Ausbildung (...) rituell geprägtes Reisen zur Voraussetzung hatte."

91 Alcock, 2001, 323 und 330, mit Verweis auf Swain, der hervorgehoben hat, dass die griechische Elite vorwiegend damit beschäftigt war, sich selber sowohl im Hinblick auf die römische Präsenz, als auch ihre eigene polis zu definieren.

92 Alcock, 2001, 324 f. in der Diskussion der Modelle des sozialen Gedächtnisses der Griechen.

93 Alcock, 2001, $326 \mathrm{ff}$.

94 Alcock, 2001, 329 f. Sie glaubt, dass besonders Autoren der Zweiten Sophistik in diesem Sinne auf die Vergangenheit fixiert waren.

95 Alcock, 2001, 333.

96 8,27,1-2: Grund der Gründung ist das Machtstreben der Arkader und dann 8,33,1: „Wenn Megalopolis, das mit allem Ehrgeiz gegründet wurde von den Arkadern und mit den größten Hoffnungen der Griechen darauf, seine ganze Ausstattung und seinen alten Wohlstand verloren hat und zu unserer Zeit größtenteils in Ruinen liegt, so habe ich mich darüber gar nicht gewundert, da ich weiß, dass die Gottheit immer etwas neues schaffen will und das Schicksal alles, das Starke wie das Schwache, das Werdende und schon Vergangene, verändert und mit starker Gewalt lenkt, wie es sein Wille ist." 
weise kanonisierenden Instanz der Erinnerung in der Person des Autors. ${ }^{97}$ Dieser Anspruch besteht auf Seiten von Pausanias auch ganz eindeutig, wie ich im Kapitel über Argos zeigen möchte, doch funktionalisiert er ihn, um Bewertungen im positiven wie negativen Sinne von Städten plausibel zu machen.

Unter diesem Gesichtspunkt erscheint auch Elsners Funktionsbestimmung von Religion in der Periegese als idealisierende Version des verlorenen vorrömischen Griechenland, das ein Amalgam von Geschichte, Mythos und Kunst sei, welches zur Kreierung eines Kanons diene, treffend. Doch während Elsner dies als ,permanente metonymische Verbindung zu einer religiösen und mythischen Realität der archaischen Zeit" interpretiert, zu der der Zugang immer noch durch Rituale und Kunst möglich ist, ${ }^{98}$ vertrete ich die Auffassung, dass bei Pausanias die Schaffung eines Kanons nicht primär auf die Religion und Kunstwerke selbst bezogen ist, sondern sie Medien sind, um eine Hierarchie der Griechen zu zeigen. Das werde ich ausführlich in den Kapiteln des dritten Teiles im Sinne Goldmanns darlegen, der die Periegese als ,ungeheure Erinnerungsarbeit bewertete, die Erinnerungsspuren der Griechen nicht nur nachfährt und inventarisiert, sondern zugleich auch deutet und kritisch auslegt (êxégesis).“99

\subsubsection{Antiker Baedeker}

Weil die topographischen Angaben, wo sie von Pausanias in der Periegese gemacht werden, zuverlässig (rrichtig‘) sind, auch wenn sie nicht von einem Fußgänger umgesetzt werden können, gibt es die sich stabil durchhaltende Auffassung, Pausanias habe einen antiken Baedeker, also einen Reiseführer schreiben wollen. Unter der Kapitelüberschrift Baedeker der Alten Welt charakterisierte etwa Casson Pausanias als Reiseschriftsteller und sein Werk als einzigen Reiseführer der Antike, der erhalten geblieben ist. ${ }^{100}$ Das Werk war ihrer Auffassung nach für „die große Masse der Touristen“ geschrieben ${ }^{101}$ und

97 Alcock, 2001, 348.

98 Elsner, 1997, 193.

99 Goldmann, 1991, 146. Dass die Reise und ihre Beschreibung durch Platons Anamnesislehre inspiriert sei und Pausanias die parádosis, die Vorbereitung auf die Mysterien, seiner Reisebeschreibung als literarische Figur zugrunde gelegt habe, so Goldmann weiter $(1991,154)$, ist eine Vermutung, die er nicht begründet hat.

100 Casson, 1976, 352. Bei Giebel, 1999, 205 ist die Periegese ebenfalls als ,griechischer Baedeker" bezeichnet. Bowie, 2001, 32 nimmt an, Pausanias' Periegese sei zwar hauptsächlich für ein gebildetes Publikum geschrieben, konnte aber auch als Baedeker benutzt werden; gegen Habicht ist Bowie nicht der Ansicht, dass die Periegese ausschließlich dafür konzipiert war.

101 Casson, 1976, 356. 
repräsentierte einen „Markstein in der Geschichte des Tourismus. “102 Es ist m. E. allein schon deshalb problematisch, die Periegese als antiken Baedeker zu qualifizieren und den Begriff Reiseführer in den Rang eines hermeneutischen Konzeptes zu erheben, weil systematische Überblicksuntersuchungen zu 'Semantiken des Reisens in der Antike immer noch fehlen. ${ }^{103}$ Whittaker plädierte zudem dafür, dass die detaillierten Beschreibungen vieler Monumente und Statuen bei Pausanias lediglich dazu gedacht waren, dass der Leser sich diese vorstellen sollte und hält daher die Auffassung, die Periegese sei ein Baedeker bzw. Reiseführer, für eine falsche Grundannahme. ${ }^{104}$ Einer der wesentlichen Gründe, weshalb das Baedeker-Theorem sich dennoch auch in Zukunft immer halten wird, ist von Osterkamp wohl treffend dargelegt worden: Bis zu Beginn des 19. Jh. und zum Teil noch darüber hinaus nämlich war Pausanias der verlässlichste und hilfreichste Griechenlandführer aus dem einfachen Grund, weil es bis dahin keine Alternativen gab. Aber auch nach der Entstehung moderner Reiseführer sei die Griechenlandbeschreibung des Pausanias das Grundbuch des reisenden Altertumsforschers geblieben, weil sich die topographischen Angaben als stimmig erwiesen. ${ }^{105}$

Widersprüche gegen das Baedeker-Theorem erzeugte sowohl in der älteren als auch neueren Forschung die Tatsache, dass es aufgrund einiger Passagen und Bücher nicht möglich ist, die Wege nachzugehen, da Pausanias seine Angaben gelegentlich systematisch und nicht topographisch anordnet. Dass auch in dieser Hinsicht die Rezeption von Roberts Buch inzwischen weggefallen ist, mag die folgende Argumentation von Robert belegen; er hatte das Baedeker-Theorem schon 1909 für endgültig überholt gehalten und es folgendermaßen dekonstruiert:

„Neben der eben geschilderten, noch heute herrschenden Vorstellung von Pausanias als antiquarischem Forscher war aber im vorigen Jahrhundert noch eine verwandte über die Tendenz seines Buches verbreitet, von der man sich jetzt zum Glück emanzipiert hat. Pausanias wollte, so glaubte man damals in allem Ernst, in diesem Werke entweder ausschließlich oder zugleich ein Handbuch für Reisende, einen rantiken Baedeker`, schaffen. Hätte er das wirklich gewollt, so würde er es so ungeschickt angefangen haben, wie nur irgend möglich. Was soll denn der Reisende mit den schier endlosen Exkursen anfangen, die nicht nur die Einleitung der einzelnen Abschnitte bilden, sondern sich breit und massig zwischen die Städteund die Denkmälerbeschreibungen einschieben? Wir stehen vor dem athenischen Bouleuterion, und Pausanias erzählt uns von den Galatern; wir durchwandern das

102 Casson, 1976, 360.

103 Den Begriff und seine Konnotationen nach der gleichnamigen Tagung des Graduiertenkollegs /Reiseliteratur und Kulturanthropologie` der Universität Paderborn, wo ich Gelegenheit hatte, einige der hier angestellten Überlegungen zu präsentieren und mit den anderen Teilnehmern zu diskutieren.

104 Whittaker, 2000-2001, 125.

105 Osterkamp, 1999, 191. 
Asklepieion, und er beschreibt uns das Gryneion; wir wollen den olympischen Zeus bewundern, und er spricht von einem Elefantenschädel in Campanien. Aber während dies nur übel angebrachte Weisheit wäre, verdiente die Unvollständigkeit der Angaben, selbst wenn man dem Autor die größte Knappheit konzedieren wollte, bei einem Reisehandbuch den allerschärfsten Tadel, um so mehr, als er das, was man z.B. in Athen zu hören erwartet, bei Boiotien nachträgt. (...) In einem Reiseführer durfte doch der Benutzer erwarten, alle diese Dinge an der ihnen gebührenden Stelle angeführt zu finden und nicht erst an dem Helikon und in Theben zu erfahren, dass die Statuen, die ihm in Athen so gefallen hatten, von der Hand des Myron und Kephisodot waren. Man hat diese Schwierigkeit wohl empfunden, und um ihr zu entgehen, zu der verzweifelten Hypothese gegriffen, Pausanias rechne darauf, dass seine Benutzer sich außerdem noch eines Fremdenführers bedienten. Von diesem konnten sie dann noch das sachlich Wichtige erfahren, während das Buch die Allotria besorgte. Dass Pausanias eine solche Voraussetzung machte, davon findet sich bei ihm nicht die leiseste Andeutung. Wohl aber gibt es eine Stelle, die direkt das Gegenteil bezeugt. Bevor er die Reliefs am Amykläischen Thron bespricht, sagt er (...). Also um seinen Leser nicht zu langweilen, sieht er von einer vollständigen Aufzählung der Reliefs ab. Dem Reisenden würde aber gerade eine vollständige Angabe der Darstellungen willkommen gewesen sein. An solche Leser denkt also Pausanias nicht. (...) So ist denn diese absurde Hypothese heutigen Tages wohl ziemlich allgemein aufgegeben. Nur in der neuesten Topographie von Athen findet sich neben manchen anderen Kompromissen auch der, Pausanias habe eine lesbare belehrende Reisebeschreibung, zugleich damit aber eine Art Reisehandbuch liefern wollen. Viel Glück auf dem Weg. (...) Das ist alles sehr klar und verständig disponiert, nur muss man den Gedanken an eine wirkliche Wanderung gänzlich ferne halten. "106

Wie im Falle der Überlegungen zum Pilgerbericht muss man sich fragen, was dann die Funktion der topographischen Angaben im Text ist. M.E. handelt es sich hierbei um eine Authentisierungsstrategie und damit konkret die Überprüfbarkeit aller seiner Angaben, die Teil seines Wissenskonzeptes ist, das ich im Kapitel 3.1.1 ausführlich erläutern werde. Darüber hinaus ist die Frage wichtig, in welchen Fällen Pausanias mehr systematisch als topographisch geordnet hat. Ich möchte dazu auf die Ausführungen von Gurlitt zu Athen zurückverweisen, der herausarbeitete, dass Pausanias keiner gehbaren Topographie folgt, sondern die topographischen Angaben systematisch so in Gruppen anordnete, dass der ganz überwiegende Teil der Peisistratidischen Monumente nicht vorkommt. Damit werden aber nicht nur die Monumente übergangen, sondern auch die entsprechenden Abschnitte der athenischen Geschichte. Die anders begründete Besonderheit in der Systematik und Topographie von Argos, d.h. die Zerstückelung der Angaben als Sinnbild der Gewalttätigkeit, wird in dem Kapitel zu dieser Stadt behandelt (3.3.1).

106 Robert, 1909, 69 f.; siehe jetzt auch Akujärvi, 2005, 17 f. 
1.7.4 Kein Proöm, kein Schluss und ein alternativer Neuansatz:

Kaschiertes Lob und Tadel der griechischen Städte und Ethnien

Gegenüber den bisher skizzierten Forschungspositionen vertrete ich im Folgenden einen alternativen Neuansatz, der im Werk ein kaschiertes (implizites) Städtelob und -tadel sieht. In welcher Weise im Einzelnen die Periegese Züge von Städtelob als auch -tadel enthält, zeige ich im folgenden Teil der Untersuchung. Durch die Annahme eines bewusst nicht nur allusiv, sondern auch verrätselt geschriebenen Textes können einige der bisher diskutierten Fragen der Pausaniasforschung neu verortet werden und Eigentümlichkeiten in der Gestaltung der Periegese erscheinen zumindest nicht mehr in sich widersprüchlich.

Schon Pasquali fragte angesichts der zahlreichen impliziten und deshalb zu erschließenden Haltungen von Pausanias prägnant: „Was hat er überhaupt mit seinem Buch gewollt"? ${ }^{107}$ Zuletzt hat Elsner eine verborgene, tiefer liegende Struktur und Bedeutung der Periegese vermutet, die man entziffern müsse. ${ }^{108}$ Dies glaube ich in der Tat auch, aber meine Analyse zielt in eine andere Richtung. Wie in Kapitel 1.2 bereits gezeigt wurde, enden Versuche, auf der Basis von Gattungsfragen sowie thematischen und systematischen Herangehensweisen die Bedeutung des Textes zu erschließen, letzten Endes immer wieder in Aporien. Dass diese Problematik hinsichtlich Pausanias' Periegese überhaupt existiert, verdankt sich dem Umstand eines ‘fehlenden` Proöms. Durch ein Proöm erklären antike Autoren normalerweise eigene Intentionen, die sie mit ihrem Werk verfolgen, welchen Vorbildern sie folgen oder auch welche anderen Autoren und Schriften sie zu widerlegen, $\mathrm{zu}$ verbessern, fortzuschreiben etc. beabsichtigen. Es wurde angesichts des nicht existierenden Proöms zur Periegese sowohl die Ansicht vertreten, dass Pausanias absichtlich kein Proöm geschrieben habe, als auch, dass es zwar ein Proöm gegeben habe, dieses aber verloren gegangen, d. h. nicht überliefert ist.

Man hat außer wegen des fehlenden Proöms auch wegen des als abrupt empfundenen Endes für eine unvollständige Überlieferung der Periegese plädiert. ${ }^{109}$ Bereits Habicht stellte ein auffallend abruptes Ende fest und konstatiert

107 Pasquali, 1913, 165.

108 Elsner, 2001, 3. Es handele sich um keine simple Reisebeschreibung, sondern die Periegese sei „orchestriert, um die Leser sowohl ideologisch als auch faktisch zu beeinflussen."

109 Zur älteren Diskussion Robert, 1909, 264 f.; er selber vertrat die Ansicht, dass Pausanias kein Proöm geschrieben habe und sah in dem allerersten Satz der Periegese eine thematische Vorausschau (chiastische Gegenüberstellung von Attika und Hellas) sowohl auf das erste Buch als auch das Gesamtwerk. Bowie 2001, 27 f. glaubt, das Proöm sei verloren gegangen. Elsner 2001, 4 entscheidet sich in der Frage eines fehlenden Proöms nicht, weißt aber darauf hin, dass das Fehlen des Proöms die Einordnung und 
m. W. als einziger eine Synchronizität von fehlendem Vorwort und Nachwort (Abschluss); jedoch problematisierte er diesen Befund nicht. ${ }^{110}$ Als Einziger ging Nörenberg davon aus, dass das abrupte Ende der Periegese ein geplanter Schluss war, und zwar hätten bei Pausanias sowohl religiöse als auch literarische Motive eine Rolle gespielt. ${ }^{111}$ Ich möchte im Anschluss an die Überlegungen von Kaivola-Bregenhøj zu kulturellen Kontexten der Rätselverwendung eine weitere Interpretation des Schlusses vorschlagen. Sie hat darauf hingewiesen, dass die „richtige“ Antwort auf eine Rätsel(metapher) sich immer am Schluss findet, das sei eine der Regeln des Spieles. Viele Definitionen von Rätsel betonen, dass wirkliche Rätsel dem Hörer genügend Informationen geben, um die Antwort zu erraten. Beschreibende Rätsel oder Rätsel im engeren Sinne könnten normalerweise ohne große Schwierigkeiten gelöst werden. Zu der Frage, wie nun also Rätsel tatsächlich gelöst werden, gibt es verschiedene Antwortmöglichkeiten, die je nach der umgebenden Kultur und der Rätselgenres variieren. In einer Rätselsituation erkennt der erfahrene Rätsellöser häufig gebrauchte klischeehafte Metaphern und kommt zur richtigen Antwort durch die Kenntnis des Genres und seines Wissens; er weiß die Antwort daher häufig schon im Voraus. ${ }^{112}$

Das vermeintlich abrupte Ende lässt sich nun aber mit dem Verschlüsselungstheorem in Verbindung bringen. ${ }^{113}$ Dann handelt es sich in Wirklichkeit nicht um ein abruptes Ende oder einen fehlenden Schluss, sondern um einen abschließenden lógos am Ende des Gesamtwerkes, der den Leser abschließend nochmals auf die Entschlüsselung hinweist $(10,38,13)$ :

„Das Heiligtum des Asklepios lag in Trümmern, ursprünglich hatte es ein Privatmann Phalysios gebaut. Als er nämlich an den Augen erkrankt und schon fast blind war, schickte ihm der Gott in Epidauros Anyte, die Ependichterin, mit einer versiegelten Schreibtafel. Das schien der Frau ein Traumgesicht zu sein, war aber sofort Wirklichkeit; und sie fand in ihren Händen eine versiegelte Schreibtafel, fuhr nach Naupaktos und befahl dem Phalysios, das Siegel zu entfernen und das Geschriebene zu lesen. Dem schien es eigentlich nicht möglich zu sein, die Buchstaben zu sehen bei dem Zustand seiner Augen; da er aber auf etwas Günstiges von Asklepios hoffte, entfernte er das Siegel, sah auf das Wachs und war gesund und gab der Anyte, was auf der Schreibtafel geschrieben stand, zweitausend Goldstatere."

Interpretation des Textes sehr schwierig macht und man mit einer Gattungszuweisung hier nicht weiterkommt.

110 Habicht, 1985, 18. Ein gewollt abruptes Ende vermutete Nörenberg, 1973, 241, und zwar als Anspielung auf die Imitation der Historien Herodots.

111 Religiös als Selbstinszenierung des frommen Pepaideumenos, der eine Episode überliefert, die den Leser an die epidaurischen Iamata erinnern soll: Nörenberg, 1973, 245.

Zum literarischen Motiv s.u.

112 Kaivola-Bregenhøj, 2001, 153.

113 Vgl. zum `offenen Schluss auch Ellinger, 2005, $210 \mathrm{ff}$. 
Ein beinahe Erblindeter entsiegelt hier also eine versiegelte Schrift. Das verleiht dem Verschlüsselungstheorem weitere Wahrscheinlichkeit, freilich keine Gewissheit. Das am Schluss des logos geforderte Honorar für die Dichterin (poiêsasan) könnte außerdem dafür sprechen, dass wir es bei der Periegese mit einer bezahlten Auftragsarbeit zu tun haben. ${ }^{114}$ Jedenfalls würde dieses $>$ abrupte Ende dem Anfang >ohne Proöm` akkurat entsprechen.

Dass Pausanias Sophist gewesen sein kann, lässt sich neben theoretischen Überlegungen zuallererst mit seinem eigenen Verständnis von Sophist(en) in Verbindung bringen. Pausanias hat im 6. Buch (Elis II) durch den Anaximenes-Logos einen Hinweis auf die Fertigkeit sophistischer Imitation gegeben. Er charakterisiert sie anhand der Person des Anaximenes (4. Jh. v. Chr.) folgendermaßen:

6,18,5: „Anaximenes scheint auch einen Feind in gelehrtester, aber auch gehässigster Weise bekämpft zu haben. Er war nämlich selber Sophist und imstande, die Ausdrucksweise der Sophisten nachzuahmen. Wie er nun in Zwist geriet mit Theopompos, dem Sohn des Damasistratos, schrieb er ein Buch gegen die Athener und zugleich über die Lakedaimonier und Thebaner, eine Schmähschrift. Da sie in genauester Weise seinen Stil nachahmte, schrieb er den Namen des Theopompos auf das Buch und sandte es in die Städte. Er hatte es also geschrieben, aber der Hass auf Theopompos wuchs in ganz Griechenland.“

Inwieweit Pausanias selbst nicht nur einen Stil und einen Autor imitierte, sondern durch die Auswahl des Beispiels auch einen Hinweis auf einen Teilaspekt seines eigenen Werkes gibt (,Schmähschrift“), muss man ernsthaft in Erwägung ziehen, wenn man bedenkt, wie z.T. abwertend seine Beschreibungen einiger Städte (z.B. Sikyon und Argos) und Griechen (z.B. Makedonen und Ptolemäer) sind. Pausanias hätte dann deshalb kein Proöm und keinen Schluss geschrieben, weil es sich um eine sophistische Imitation gehandelt hat, die der Leser erraten sollte. Ähnliches hatten bereits Robert und andere Forscher vor ihm vermutet. Ihre Annahme wurde jedoch vor einem anderen Hintergrund geäußert: Robert selbst hielt Pausanias $u$.a. für einen Sophisten, weil er, wie er meinte, mit seinen Lesern „Versteck spiele“ und die Leser vieles erraten sollten. Robert sah als das typisch für Vertreter der Zweiten Sophistik an. ${ }^{115}$

Alle Rätselsituationen beinhalten eine Form von Wettbewerb, einen Test des Wissens des anderen. Es gibt immer zwei sich gegenüberstehende Parteien, von denen die eine ein spezielles Wissen besitzt, und mit dem sie die andere Partei testet. ${ }^{116}$ Das fehlende Proöm und der fehlende Schluss bieten demnach

114 Nörenberg, 1973, $248 \mathrm{f}$. hat herausgearbeitet, dass der Auftrag der Dichterin von Pausanias in den Mittelpunkt der Erzählung gestellt und der Erhalt des Honorars so zur Pointe gestaltet wurde.

115 Robert, 1909, 29.

116 Kaivola-Bregenhøj, 2001, 152. 
nur einen Hinweis darauf, dass der Autor mit Verrätselung gearbeitet hat; hierzu gehören eine Reihe von weiteren Fragen, die der Leser erraten bzw. beantworten soll. An erster Stelle stehen dabei die Fragen, um was für eine Art von Schrift es sich bei der Periegese handelt und wen er damit imitiert bzw. stilisiert. Ich werde dementsprechend im nächsten Teil der Untersuchung zunächst zeigen, dass es sich bei der Periegese um ein verrätseltes, kaschiertes Lob und Tadel handelt. Im dritten Teil analysiere ich die Wahl des mutmaßlichen Vorbildes für die Imitation (Polemon von Ilion), die Strategien, die er verwendet, um seinen Beschreibungen Authentizität zu verleihen und seinen Wertungen und Hierarchisierungen eine entsprechende Autorität. 